\title{
The effect of coupled wear and creep during grid-to-rod fretting
}

\author{
HaiWang $^{\mathrm{a}}$, Zupan $\mathrm{Hu}^{\mathrm{a}}$, WeiLu ${ }^{\mathrm{a},{ }^{*}}$ and M. D. Thouless ${ }^{\mathrm{a}, \mathrm{b},{ }^{*}}$ \\ ${ }^{a}$ Department of Mechanical EngineeringUniversity of Michigan \\ Ann Arbor, $M I$ 48109, USA \\ ${ }^{b}$ Department of Materials Science \& Engineering \\ University of Michigan, Ann Arbor, MI 48109, USA
}

* Corresponding author.

E-mail addresses: weilu@umich.edu (W. Lu), thouless@umich.edu (M. D. Thouless) 


\begin{abstract}
The initial stages of grid-to-rod fretting (GTRF) is associatedwith stress-relaxation. Both creep and wear contribute to this process. These mechanisms act in concert, and are influenced by each other. The development of a strategy to couple creep and wear is important for the numerical modeling of gap formation in a pressurized-water reactor(PWR). However, thecharacteristic time scales for the two processes are very different, which can cause numerical problems. In this paper, an approach is presented to develop reasonably efficient, yet accurate,models that couple the two processes. This approach is used for a numerical analysis of gap formationduring grid-to-rod fretting. In this analysis, the effects of wear are integrated with the effects of creep relaxation, providing insight into the relative roles of the two mechanisms in this particular application.During the early stages of gap formation, the fluid-induced excitation forces are not large enough to cause macroscopic slip and wear across the entire interface. As a result, creep, rather than wear, is the dominant mechanism that dictates the evolution of the contact stress. Creep contributes to stress relaxation both through the creep-down of the cladding onto the fuel, and by local stress relaxation at the contacts. Although localized wear always occurs at the edge of the contacts, the effects are so small that this can be considered to be an incubation period for wear. Eventually, the contact force relaxes to such an extent that slip occurs over the entire contact between the pin and cladding, and wear becomes the dominant relaxation mechanism. The simulations demonstrating these concepts explored different pressure fluctuations, friction coefficients, wear coefficients, and initial interference, to show how these different parameters affect the wear profile and the time at whichcontact is lost between the grid and cladding.
\end{abstract}

(April7, 2017) 


\section{Introduction}

Grid-to-rod fretting (GTRF) induced by turbulence in the coolant can cause wear of the zirconium alloy used as cladding for the fuel inpressurized-water reactors [Kim, 2009]. This wear mechanism is a major causeof leaking fuel, and is a significant concern for the design and safety of reactors. The contact pressure between the grid and cladding, which can relax as a result of both wear and creep, controls the wear rate.Eventually, the contact pressure can relax to such an extent that a gap opens up between the two components. Once this happens, the wear process changes to one associated with dynamic impact [Kim and Suh, 2009; Lee and Kim, 2013]. Modeling the first stage of the fretting process, where wear and creep interact, is complicated by the fact that the two processes are associated with very different time scales. The question of how to integrate the two time scales into a numerical model of GTRFis the focus of the present study.

There are twotypes of frictional interaction across an interface: sticking and slipping [Churchman and Hills, 2006].Sticking occurs wherever the friction coefficient issufficiently high to prevent relative sliding between the two surfaces. Ifthe contact stressrelaxessufficiently by creep, for example,thenthe two components can slide relative to each other, and wear can occur at the interface. Full slip occurs when there is sliding along an entire contact area. Partial slip occurs when the slip condition is met on only a portion of theinterface (usually close to the edge of a contact where the shear stresses tend to be the highest).

Creep and wear can have very different characteristic times; this discrepancy needs to be addressedwhen developing numerical models for the combined phenomena. For example, the coolant in a reactor causes the rods to vibrate atrelatively high frequencies [Kim and Suh, 2008, 
Rubiolo and Young, 2009].To capture the wear associated with each cyclewould require very small time increments. However, creep processes can take place over much longer time scales, depending on the stress level. The use of time increments short enough to describe each wear cycleindividually would not be an efficient way to model creep. Conversely, the use of time increments large enoughto model creep efficiently would correspond to many wear cycles. The error associated with this could lead to inaccuracies inboth wear and creep calculations. This is the issue that motivated the work described in this paper, in which we discuss the use of an algorithm todetermine the appropriate time incrementsthat should be used to couple the two mechanisms efficiently, but without significant loss of accuracy.

Conventional re-meshing algorithms to model a wear scar introduce another numerical problem when trying to couple wear with creep. Re-meshing requires unloading the model; thiscan cause loss of the loading history for the system. To overcome this difficulty, we use aneigenstrain algorithm developed by Hu et al. [2015] to model wear. This algorithm allows the wear-scar profile to be updated dynamically without re-meshing, so the stress history is maintained continuously. This feature makes the algorithm particularly useful in the coupled wear-creep problem.

Acomplication associated with numerical models of creep is that the mechanism for stress relaxation depends upon the temperature and stress level. So, the creep law can change during the relaxation process. To address this issue, we use the creep model developed by Wang et al. [2013], in which a deformation map of zircaloy-4is embedded withinthe finite-element code, allowing the dominant mechanism to evolve naturally as the conditions change. 
In summary, in this paper we present a numerical analysis of pin-on-grid wear during a prolonged operation cycle for apressurized-water reactor.The primary purpose of thework is to illustrate how one can couple creep and wear, and to examine the regimes in which wear or creep control the stress relaxation. We are not attempting to do a detailed analysis of wear scar formation. There are too manyparameters that are currently unknown in sufficient detail. So, while the model includes some effects such as creepand swelling of the fuel for which we have access to reasonable models or empirical data,we have not included important effects such as radiation creep, radiation growth, hydride formation, or oxidation. The important results of this paper are to show how one can couple creep and wear in a numerical simulation, and to illustrate the types of behavior that might occur prior to gap formation between the rod and grid.

\section{Optimization of the time steps}

During the operation of a reactor, the coolant exerts a randomvibrationpressure on the cladding surface. However, for the purposes of this study, we assume that the pressure, $P$, can bedescribed by a periodic sinusoidal formwith a period of $T_{o}$ that is in the range of $0.001 \mathrm{~s}$ to 0.1s[Rubiolo and Young, 2009; Yan et al., 2011].

Within a single periodof such a short duration, neither creep nor wear will cause significant changes to the geometry or to the contact pressure. Therefore, the rate of wear over a limited computational interval, $T_{\mathrm{e}}$, greater than $T_{o}$, will be constant. The wear damage that accumulates over such a period can be approximated reasonably accurately by calculating the wear over one cycle, but multiplying the wear coefficient by the ratio $T_{e} / T_{o}$. Thisreduces the number of cycles that have to be calculated, and makes the simulation more efficient. However, the important question is how to ensure that $T_{\mathrm{e}}$ issmall enough so that anychanges in the contact pressurethat occur during thisintervaldon't affect the solution. 
Optimizing the computational interval, $T_{\mathrm{e}}$, requires a balance between efficiency and some small loss of accuracy associated with changes in the contact pressure that must occur because of bothwear and creep during this time. A criterion can be established in the form of limiting the maximum allowable decrease in the contact pressure, $\Delta p$, at any point along the interface ${ }^{1}$ to someacceptable fraction, $\varphi$, of the maximum contact pressure across the interface, $p_{\max }:$

$$
\Delta p<\varphi p_{\max } \quad .
$$

A companion study [Hu et al.,2016], has shown that choosing a value of $\varphi$ less than about 3\% is more than adequate to provide solutions that are essentially independent of $\varphi$.

One numerical approach to this problem is to replace a block of vibrational cycles with a single, lower-frequency cycle and use an enhanced wear coefficient to correct for the number of cycles. However, such an approach neglects the possibility that creep alone can cause relative slip across an interface, and that this relative slip can contribute to wear. It would be wrong to use an enhanced wear coefficient when calculating wear from any slip induced by creep. Therefore. the interfacial slip resulting from the two phenomena needs to be separated.

To separate the two contributions to interfacial slip, the periodic excitation pressureis replaced by the pressure history shown in Fig. 1. At the beginning of each new computational interval, two cycles of oscillation are used to calculate the wear rate in a single cycle. A steadystate is established in periodic slip calculations after the first cycle; so, the wear rate for a single cycle is calculated from the second cycle. After the second cycle, the oscillating pressure

\footnotetext{
${ }^{1}$ The contact pressure at each node, or the average contact pressure across the interface, could also be used in Eqn. 1. However, our studies suggested that the use of the maximum contact pressure across the interface was the best approach.
} 
is set to zero for the rest of the computational interval, $T_{e}$; during this period, creep relaxation can occur. At the end of the computational interval, the local wear at every point along the interface is calculated using the enhanced wear coefficient for the damage induced by the cyclic loading, and the regular wear coefficient for wear induced by any creep deformation. At this stage the resultant change in contact pressure is calculated along the interface to investigate how it compares with the pre-established criterion, and whether the computational interval needs to be decreased for accuracy, or increased for efficiency.

\section{Model}

\section{$\underline{3.1 G e o m e t r y ~ a n d ~ b o u n d a r y ~ c o n d i t i o n s ~}$}

A two-dimensional model was constructed to simulate the contact between the grid andcladding (Fig. 2), using the commercial finite-element code ABAQUS [ABAQUS, 2011]. A simplified model of a single cell was considered, with a symmetry planeat $45^{\circ}$ to the horizontal ( $x$-axis)along which sliding can occur. The default contact elements of ABAQUS were placed on top of the eigen-strain elements used to model wear [Huet al., 2015] along all surfaces that could potentially form a contact between the cladding and grid. Coulomb frictionwas assumed for allinterfaces. $^{2}$ Since the coefficient of friction forzirconia surfaces depends on environment [Fischer et al., 1988], and may be different from that for zirconium, various values were assumed for the coefficient of friction in the range of0.1 to 0.7.The contactswere modeled with a hardcontact, surface-to-surface formulation,with finitesliding.The "direct" property was used for the

\footnotetext{
${ }^{2}$ Models of constant shear strength are appropriate for analyses of friction at individual asperities or nano-scale contacts [Homolaet al., 1990; Gao et al., 2008], or for singular fields [Hu et al., 2015]. However, Coulomb's law is generally applicable for macroscopic problems of the type considered in this paper because, with sufficient scales of roughness much smaller than the nominal contact area, the actual area of contact increases approximately linearly with pressure, giving rise to Coulomb's Law [Bowden and Tabor, 1950; Barber, 2013].
} 
normal direction[ABAQUS, 2011]. For the tangential direction, the Lagrange multiplier approach has convergence problems, especially when many nodes are iterating between sticking and slipping. Therefore, the alternativepenalty method was used, withan elastic-slip toleranceof $1 \times 10^{-6}$ to improve accuracy [ABAQUS, 2011].

An assumed misfit between the cladding and grid, associated with assembly, was established at a reference temperature of $300 \mathrm{~K}$. This was done by imposing a displacement on the constrained surfaces of the grid (Fig. 2) beyond that required for the grid just to make contact with the surface of the cladding. Once this misfit had been imposed, the calculations were subsequently conducted using the thermal and pressure conditions appropriate for the service of reactors.

The thermal boundary conditions for the problem were established by assuming that the power production in the fuel had a uniform value of $15 \mathrm{~W} / \mathrm{mm}$ [Romano et al., 2009], and that the temperature of the outer surface of the cladding was $600 \mathrm{~K}$, corresponding to the temperature of the coolant.The temperature-dependent thermal conductivities and the specific heats for the zircaloy and fuelwere taken from MATPRO models[Allison et al., 1993].It was assumed that there was an initial gap of $0.08 \mathrm{~mm}$ between the inner surface of the cladding and the outer surface of the fuel. The gas in this gap was assumed to be helium with a thermal conductivity of0.00264 $T^{0.71} \mathrm{~W} / \mathrm{m} \mathrm{K}$ [Allison et al., 1993], where $T$ is the average temperature between the inner surface of the cladding and the outer surface of the fuel.This value of thermal conductivity for a gas wasused until direct contact between the fuel and cladding occurred.

The mean level of the pressure outside the cladding was set to16 MPa, and an internal gas pressure of $4 \mathrm{MPa}$ was assumeduntil contact occurred between the fuel and the cladding[Johnson 
et al., 1982; Johnson et al., 1983]. In addition,a sinusoidal pressure with an amplitude of $P_{o}$ and a period of $T_{o}=0.1 \mathrm{~s}$ was assumed to act on the section $B C$ of the exterior surface of the cladding,with a corresponding out-of-phase pressure acting on section AF.This resultedin an oscillatory motion along the symmetry plane, and identical wear on the contacts $E F$ and $D C$. The amplitude of the pressure, $P_{o}$,was assumed to vary between 0 and $0.04 \mathrm{MPa}$, as this corresponds to arange ofexcitation forces ofup to $0.5 \mathrm{~N} / \mathrm{mmcited}$ in the literature [Bakosiet al., 2013; Yan et al., 2011]. In the calculations, the periodic loading was replaced by a pressure-time history of the form shown in Fig. 1. As discussed in Section 2, this was done to allow creep and wear to be coupled efficiently.

\subsection{Wear and creep models}

The wear rate was calculated using Archard's law [Archard, 1953]. In the twodimensional formulation used in this study, the incremental wear depth, $W(s, t)$, at any location along a contact, $s$, and at a given time, $t$, was calculated by

$$
\frac{\partial W}{\partial \Lambda(s, t)}=\mu K p(s, t)
$$

where $K$ is the wear coefficient, $p(s, t)$ is the local contact pressure, $\Delta(s, t)$ is the local relative slip between the two surfaces, and $\mu$ is thefriction coefficient. During the numerical simulations, both the local pressure and the slip across the contact were calculated using the ABAQUS subroutine, URDFIL. ${ }^{3}$ Wear coefficients between $5 \times 10^{-8} / \mathrm{MPa}$ and $2 \times 10^{-7} / \mathrm{MPa}$ have been reported in the literature [Fisher et al., 2002; Cho et al., 1998; Blau, 2014], which was the range we chose to explore here.

\footnotetext{
${ }^{3}$ ABAQUS outputs the contact information for the "slave" surface only. URDFIL acquires the contact information only for nodes on the "slave" surface, so only the pressure and slip on the "slave" surface, set in this study to be the cladding surface, can be calculated. Therefore, the contact regions of both the grid and the cladding were meshed identically, and the wear was assumed to be the same for both surfaces.
} 
The numerical algorithm developed by Hu et al. [2015] was used to simulate the wear profile. This algorithm uses a set of surface elements that accommodateschanges in geometry, such as those induced by wear, by ascribing fictitious eigenstrains to them. Theeigenstrainscorrespond to the local wear depths, and can be incorporated into calculations using ABAQUS UEXPAN subroutine. These wear elements were placed over all regions where contact could possibly occur between the grid and cladding. The thickness of these elements was $0.010 \mathrm{~mm}$, whereas the thickness of the cladding was $0.57 \mathrm{~mm}$, so the properties of these elements had a negligible effect on the solution. ${ }^{4}$

The thermal expansion of both the zircaloy and the $\mathrm{UO}_{2}$ were implemented using the ABAQUS UEXPAN subroutine. Creep and swelling phenomena were implemented with the ABAQUS CREEP subroutine. Values for the thermal expansion and elastic properties of zircaloy, and for the elasticity, thermal expansion, and swelling of $\mathrm{UO}_{2}$ were taken from MATPRO models [Allison et al., 1993].Anisotropic values for the thermal expansion of zircaloy were included in the model, but isotropy was generally assumed for the calculations. Mechanism-based creep models were incorporated into the finite-element analyses, as described by Wang et al. [2013], to simulate creep of the cladding, grid, and fuel. The parameters for the zircaloy creep mechanisms were taken from the models developed by Wang et al. [2013], while the parameters for the $\mathrm{UO}_{2}$ creep mechanisms were taken from the deformation-mechanism map for $\mathrm{UO}_{2}$ given by Frost and Ashby [1982].Although the effects of grain size in the zircaloy are discussed later, it was initially assumed to be $50 \mu \mathrm{m}$, whilethe grain size of the $\mathrm{UO}_{2}$ was assumed to be $10 \mu \mathrm{m}$.

\footnotetext{
${ }^{4}$ It was noted in $\mathrm{Hu}$ et al. [2015] that the eigenstrain algorithm can cause fictitious stresses in the surface elements.However, it was verified that thesestressesdidn't have a significant effect on the results presented here.
} 
The creep-down of the claddingcausedbythe external pressure causes dimensional changes to the cladding; these dimensional changes contribute to the reduction in contact force for this particular problem.In the results section, this phenomenon of relaxation associated with global dimensional changes resulting fromcreep-down of the claddingis considered separately from the relaxation caused by local creep at the contact, so as to evaluate which phenomenon is more significant in this problem.

Although the dimensional change of the $\mathrm{UO}_{2}$ associatedwith swelling during burn-up is included in this analysis, the initial loss of contact between the cladding and grid occurs before the cladding creeps down onto the fuel. Therefore, the subsequent expansion of the cladding induced by the swelling of the $\mathrm{UO}_{2}$ does not feature in the results presented here.

Mesh-sensitivity analysesshowed that a mesh size of $8 \times 10^{-3} \mathrm{~mm}$ along the contact interface was more than adequate to ensure that the wear profile and contact forcewereindependent of mesh size once full slip occurred. However, a slightly finer mesh size of $1.6 \times 10^{-3} \mathrm{~mm}$ was required to capture thedetails of the wear profile developed during the initial stages of partial slip. Therefore, in the results that follow, the wear profiles associated with partial slip were obtained usinga mesh size of $1.6 \times 10^{-3} \mathrm{~mm}$, while all the other wear profiles wereobtainedusing a mesh size of $8 \times 10^{-3} \mathrm{~mm}$.Additionally, 11 layers of elements across the thickness of the grid and cladding were used to ensure that the contact force and wear profile were mesh independent.The calculationswere implicit, with the elements being first-order, coupled temperature-displacement,plane-strain elements with reduced-integration points (CPE4RT). 


\section{Results and discussion}

In this section we explore the relative importance of creep and wear on the stress relaxation that leads to slip, to the development of a wear scar, and to the eventual loss of contact between the cladding and grid. In this context, it is noted that there are two manifestations of creeprelaxation in this problem: it can cause relaxation of the local contact stresses directly owing to creep at the contact region, and it can also cause general relaxation because of the creep-down of the cladding onto the fuel. The approach we take in this paper is to model different problems, and then selectively "switch off" phenomena whose effects we wish to explore to identify its contribution.

Since there is uncertainty about the value of several parameters, the results are presented in a non-dimensional form. In particular, the Young's modulus of zircaloy-4 at $600 \mathrm{~K}$, $E=71.6 \mathrm{GPa}$, the outer radius of the cladding, $R=4.75 \mathrm{~mm}$, the cladding thickness, $h=0.57 \mathrm{~mm}$, and the natural period of the excitation pressure, $T_{o}=0.1 \mathrm{~s}$, are used to normalizethe normal contact force, $N$, the wear depth, $W$, the time, $t$, and the distance from thecenter of the contact region, $x$.

\subsection{Relaxation from creep only}

Creep can relax the stresses at the contacts. In particular, diffusional creep alone can reduce the contact stresses to a very low level within the operating cycle of a reactor. Often the analysis of creep in zircaloy focuses only onpower-law creep. Figure 3a emphasizes why diffusional creep must be included in long-term analyses, because it becomes the dominant mechanism at low stresses. This figure shows that if diffusional creep is "switched off", and only power-law creep is assumed to operate, the long-term stresses are much higher. This would result in an underestimate of the extent of slip and wear. 
Figure 3bseparates the role of creep-down from the role of local stress relaxation at the contact. By setting the gauge pressure to zero, the only creep process that can relax the stresses is the local relaxation at the contact.Also, to compensate for the effect of removing the gauge pressure on the initial contact force, an initial gap of $6.75 \times 10^{-3} \mathrm{~mm}$ was introduced into the model, to keep the initial contact force the same. It is clear that creep-down plays a dominant role in the relaxation of the stresses at the contacts in this particular problem.

\subsection{Relaxation from wear only}

The geometry of the contact at the pinsis similar to that of a Hertzian contact. The wear behavior for such a problem is well-known [Barber, 2010; Goryachevaet al., 2001]. If the coefficient of friction is less than the ratio of the shearing force to the normal contact force, the entire interface will slip, and a wear scar will develop across the entire contact. If the coefficient of friction is high enough to prevent full slip, partial slip will occur at the edges of the contact. This will lead to localized wear scars at the edges of the contact. However, in a perfectly elastic system with only Coulomb friction, the wear scar will not propagate [Goryachevaet al., 2001]. Propagation of the wear scar requires either a finite interfacial strength [Hu et al., 2015a], or some form of plasticity [Hu et al., 2016].

Figure 4 shows that creep is another mechanism that allows the wear scar to propagate beyond the initial slip region. If there is no creep, wear only occurs in the initial slip region. The scar gets deeper with time, it doesn't extend. With the misfit and turbulent pressures assumed in this study, only unrealistically low values of friction coefficient would permit full slip across the contact in a perfectly elastic system. Without any creep, the region of slip would be limited to a very small portion of the interface, and the stress-relaxation associated with wear alone would be negligible. 


\subsection{Combined creep and wear}

A major effect of creep during the wear process is to permit the wear scar to extend. This is illustrated by the curve in Fig. 4 thatcompares the wear scar that evolves at a fixed time when there is creep, to the scar that evolves without creep. Since the region of slip andwear propagates across the interface in the presence of creep, a condition of full-slip eventually develops at the contact. This accelerates the wear process, which, in turn, reduces the time it takes for contact to be lost. An example of how the contact force decays when there is only creep, rather than combined creep and wear, is shown in Fig. 5. It can be seen that significant acceleration in the relaxation of the normal contact force occurs once full-slip develops. However, as discussed above, this state of full-slip can only occur in the presence of creep (except under extreme conditions, with very large sliding forces).

The wear profiles corresponding to the calculations of Fig. 5 are shown in Fig. 6, at different times in the cycle. Initially, wear occurs just at the edges of the contact, where there is slip. Creepallows the wear damage to progress towards the center of the contact. Eventually, full-slip occurs, resulting in wearalong the entire interface. This results in a final wear profile that has a maximum depth in the middle of the contact.

Figure 7 shows the same data for the evolution of the wear profile in the full-slip regime as shown in Fig. 6b, but now the data are plotted in a form that shows how thewear profiles at different times collapse into a single master curve. The existence of such a master curveprovides

a useful way of presenting wear scars non-dimensionally, as has been observed andexplained by other authors[Paulin et al., 2008]. According toArchard's law, the wear rate will be higher at any point within a contact where the pressure is higher. The resultant increase in the local wear rate will cause the local pressure todrop and, eventually, the pressure will become uniform across 
the contact. Once the contact pressure is uniform, the wear rate also becomes uniform, and a steady-state profile evolves.

\subsection{Effects of friction coefficient, wear coefficient and amplitude of excitation force}

Figure8 shows the effects of friction coefficient (in the range of 0.1 to 0.7 [Fischer et al., 1988]), wear coefficient (in the range of $5 \times 10^{-8}$ to $2 \times 10^{-7} / \mathrm{MPa}$ [Fisher et al., 2002; Cho et al., 1998; Blau, 2014]), and amplitude of theexcitation pressure(consistent with excitation forces in the range of 0 to $0.5 \mathrm{~N} / \mathrm{mm}$ [Bakosiet al., 2013; Yan et al., 2011]) on the relaxation of the normal contact force as a function of time. The onset of full-slip in these plots can be identified by the sudden increase in the relaxation rate. These figures show the expected results that the onset of full slip can be delayedeither by decreasing the amplitude of the excitation force or by increasing the coefficient of friction. The loss of contact occurs later if full slip is delayed. There is no effect of wear coefficient on the onsetof full slip, but once full slip occurs loss of contact occurs more quickly for higher wear coefficients.

As discussed above, the wear profile grows homogeneously during the full-slip stage.Therefore, the wear profile corresponding to any particular value of maximum wear depth can be obtained from the master curve. This is shown in Fig. 9(a). Furthermore, as shown in Fig. 9(b), a systematic study of the effect of different variables shows that the depth of the wear scar when contact is lost, $W_{\max }$, depends on the non-dimensional group $P_{o}^{2} K n_{f} / E$, where $n_{f}$ is the number of wear cycles of full slip. This can be justified by a simple analysis of Archard's law (Eqn. 2). The springs ensure that equilibrium is maintained until a gap is formed, so the slip distance is proportional to the applied pressure and is inversely dependent on the stiffness of the system. The total slip distance is also proportional to the number of cycles before contact is lost. It is of interest to note that the wear depth at which contact is lost does not depend on $\mu$. A lower 
value of $\mu$ results in less wear, but more cycles are needed to lose contact. This can be seen by the result for vary low value of $\mu=0.01$, which sits on the master curve. The two plots shown in Fig. 9 provide a general way of presenting the development of the wear scar in a fashion that is not sensitive to the variables that are particularly poorly known for this problem $-\mu, P_{o}$ and $K$.

\subsection{Effect of initial misfit}

Figure 10 shows the effect of a misfit introduced during assembly, $d$, on the relaxation of the normal contact force. Abigger misfit can delay the onset of gap formation, butthis delay is not very significant because the initial relaxation rate is dominated by power-law creep, which is much faster at the higher stresses induced by a bigger misfit. However, the presence of an initial gap during assembly (which can then be closed up by thermal expansion when the system first enters into service) results in a much quicker gap formationduring service. Figure 11 shows that the initial misfit determines the details of the master curves for the wear profile and the wear depth.In both these figures, the final wear depth required to cause loss of contact reflects the magnitude of the initial misfit.

\subsection{Effect of zircaloy grain size}

Figure 12(a) shows the effect of the zircaloy grain size on the relaxation of the normal contact force. Figure 3a emphasizes the importance of diffusional creep at low stresses. Since the diffusional creep rate increases as the grain size decreases, the effect of diffusional creep on the relaxation ofthe normal contact force becomes more important with a smaller grain size. Figure 12(b) shows that the maximum wear depth decreases as grain size increases. With a larger diffusional creep rate at a smaller grain size, contact force relaxes in a faster rate. As a result, 
small wear depth is expected for a small grain size. Also, the master curve of thefinal wear profile is independent of the grain size as expected.

\subsection{Effect of irradiation growth}

The model was further modified to study the effect of irradiation growth on the relaxation of the normal contact force. The equation for irradiation growth was taken from the MATPRO model [Allison et al., 1993]:

$$
\varepsilon_{i i}=1.407 \times 10^{-16} e^{240.8 T}(\phi t)^{0.5}\left(1-3 f_{i}\right)(1+2 C W)
$$

where $\varepsilon_{i i}$ is the strain in thei direction, $T$ is the temperature in $\mathrm{K}$ (assumed to be between $313 \mathrm{~K}$ and $633 \mathrm{~K}$ ), $\phi$ is the fast neutron flux, which is assumed to be $3 \times 10^{17} \mathrm{n} / \mathrm{m}^{2}$ s [Allison et al., 1993], $t$ is time [s], $f_{i}$ is the fraction of grains with the $c$-axis oriented along thei direction, and $C W$ is the reduction in cross-section area caused by cold work, whichis assumed to be $25 \%$.

Up to this point in the paper, we have assumed an isotropic microstructure, since the effects of anisotropy on any of the model parameters are probably less than any other uncertainties. However, the effects of irradiation growth depend on the texture; there is no growth in an isotropic material for which the texture factors in each direction are equal: $f_{i}=0.33$. Therefore, for the purposes of this simulation, we assumed texture factors of 0.66 in the radial direction, 0.28 in the hoop direction, and 0.06 in the axial direction which are consistent with results in the literature[Kearns and Woods, 1966; Allison et al., 1993]. This results in significant elongation in the axial direction, some elongation in the hoop direction, and shrinkage in the radial direction. The simulation described in the earlier sections was run including the effects of texture; the main effect of texture was irradiation growth, but its very minor effect on thermal expansion was also included. Figure 13 illustrates that these additional effects of texture have a 
negligible effect on the relaxation of the contact force and the time to form a gap, compared to the effects of diffusional creep.

\section{Conclusions}

In-pile relaxation of the contact force is a significant reason forthe development of a wear scar during grid-to-rod fretting. Both wear and creep are responsible for this relaxation of the contact force, and a model has beendeveloped to couple the two mechanisms. The two processes occur at different time scales. Wear is associated with fluid-induced vibrations at relatively high frequencies, so the time increment of any wear simulation needs to be fairly small. However, creep occurs over relatively long time scales, and a time increment based on the vibration frequency is not efficient for creep simulation. Therefore, an optimization method had to be developed to couple the two mechanisms in a fashion that combines an acceptable level of both efficiency and accuracy. This was done by developing an effective cycle, with a varying period that depended on keeping the changes in normal contact pressure constant within some acceptable limit.

One of the important contributions of creep to the wear process is that it allows a wear scar to propagate across the entire contact. In a purely elastic system slip occurs only at the edges of a contact. Any wear scar that develops in such a system does not grow with time; it just gets deeper. However, creep relaxes the high stresses at the slip-stick boundary, allows the region of slip (and wear) wear to propagate across the contact. This process eventually leads to full slip across the entire contact, and the rate of wear increases significantly. Since the wear damage before the onset of full-slip may be relatively minor, the time taken for the slip zone to propagate across the entire interface may be manifested as an incubation period for wear damage. 
The other aspect of creep that plays an important role in the wear process is stress relaxation. This can be the result of both creep-down of the cladding onto the fuel, and of local stress relaxation at the contacts. Creep-down appears to be more important in this particular problem. Power-law creep is dominant at the initial stages of relaxation, when the stresses are high. However, diffusional creep eventually becomes dominant. It is this mechanism that is responsible for reducing the contact stresses to a very low level within the operating period of a reactor, allowing full slip to occur across the contact. Owing to the dominance of diffusional creep on the relaxation process, the grain size of the zircaloy will have a large effect on the time taken for gap formation, with smaller grains resulting in a faster loss of contact.

By coupling the two mechanisms, simulations were conducted assuming different friction coefficients, excitation pressures, wear coefficients and initial misfits to explore how the different parameters affect both the wear profile and the time at which the grid and cladding lose contact. The simulationsindicate that two stages exist during the relaxation of the contact force: partial slip and full slip. When partial slip occurs, the dominant relaxation mechanism is creep.During this regime, the wear scar propagates across the contact, and there is a transition to full-slip. Once full-slip occurs across the entire interface, and the contact forces are relatively low, the creation of a wear scar becomes the dominant relaxation mechanism. In this regime, reducing the wear coefficient andthe amplitude of excitation force delays the formation of a gap between the grid and cladding.

As is intuitively obvious, an initial gap between the grid and cladding created during assembly results in the quicker formation of a gap during service. Conversely, an initial misfit between the clad and pin will delay the gap formation. However, stress relaxation by power-law 
creep is more rapid at high stresses, so any stress induced by an initial misfit tends to get relaxed relatively quickly. This means that there is limited benefit to increasing the initial misfit.

The wear profile developed during full-slip occurs homogeneously. For a given initial interference, there is a master curve for the wear scar, which does not depends on the friction coefficient, the amplitude of the excitation pressure, or the wear coefficient. Therefore, the wear profile is defined by the maximum wear depth that depends on the product of the square of the excitation pressure times the wear coefficient and the number of wear cycles. The existence of such a relationship means that the results presented in this paper can be used to estimate the effects of the parameters that may be particularly ill-defined for the GTRF problem.

\section{Acknowledgements}

This research was supported by the Consortium for Advanced Simulation of Light Water

Reactors (http://www.casl.gov), an Energy Innovation Hub (http://www.energy.gov/hubs) for Modeling and Simulation of Nuclear Reactors under U.S. Department of Energy Contract No. DE-AC05-00OR22725. 


\section{References}

ABAQUS user’s and theory manuals, Version 6.11, Simulia, Dassault systems,2011.

J. F. Archard, “Contact and rubbing of flat surfaces,”Journal of Applied Physics, 24, 981-988, 1953.

C.M. Allison, G.A. Berna, R. Chambers, E.W. Coryell, K.L. Davis, D.L. Hagrman, D.T. Hagrman, N.L. Hampton, J.K. Hohorst, R.E. Mason, M.L. McComas, K.A. McNeil, R.L. Miller, C.S. Olsen, G.A. Reymann and L.J. Siefken, "SCDAP/RELAP5/MOD3.1 Code manual Volume IV: MATPRO -- Alibrary of materials properties for light-water-reactor accident analysis (MATPRO)," NUREG/CR-6150, EGG-2720, Volume IV, 1993.

J. R. Barber. Elasticity. Springer, Netherlands, 2010.

J. R. Barber, "Multiscale Surfaces and Amontons' Law of Friction," Tribological Letters, 49, 539-543 (2013).

P. J. Blau, “A multi-stage wear model for grid-to-rod fretting of nuclear fuel rods”, Wear, 313, 89-96, 2014.

J. Bakosi, M. A. Christon, R. B. Lowrie, L. A. Pritchett-Sheats, R. R. Nourgaliev, "Large-eddy simulations of turbulent flow for grid-to-rod fretting in nuclear reactors,"Nuclear Engineering and Design, 262, 544-561, 2013.

F. P. Bowden, and D. Tabor, The Friction and Lubrication of Solids, Clarendon Press, Oxford, UK (1950)

C.M. Churchman and D.A. Hills, "General results for complete contacts subject to oscillatory shear,” Journal of the Mechanics and Physics of Solids, 54, 1186-1205, 2006.

K. H. Cho, T. H. Kim, S. S. Kim, “Fretting wear characteristics of Zircaloy-4 tube,” Wear, 219, 3-7, 1998.

H. J. Frost and M. F. Ashby, "Deformation mechanism maps: the plasticity and creep of metals and ceramics,"Pergamon Press, Oxford, UK, 1982. 
N. J. Fisher, M. K. Weckwerth, D. A.E. Grandison, B. M. Cotnam, "Fretting-wear of zirconium alloys,”Nuclear Engineering and Design, 213, 79-90, 2002.

T. E. Fischer, M. P. Anderson, S. Jahanmir and R. Salher, "Friction and wear of tough and brittle zirconia in nitrogen, air, water, hexadecane, and hexadecane containing stearic acid,” Wear, 124, 133-148, 1988.

I. G. Goryacheva, P. T. Rajeev and T. N. Farris, "Wear in partial slip contact,"Journal of Tribology,123, 848-856, 2001.

Y. F. Gao, H. T. Xu, W. C. Oliver, G. M. Pharr, “A Comparison of Coulomb Friction and Friction Stress Models Based on Multidimensional Nanocontact Experiments”, Journal of Applied Mechanics, 75, 034504-1-3, 2008.

A. M. Homola, J. N. Israelachvili, P. M. McGuiggan and M. L. Gee, "Fundamental Experimental Studies in Tribology: The Transition from "Interfacial" Friction of Undamaged Molecularly Smooth Surfaces to "Normal" Friction with Wear," Wear, 136, 65-83 (1990).

Z. Hu, W. Lu, M. D. Thouless, and J. R. Barber, "Simulation of wear evolution using fictitious eigenstrains,”Tribology International, 82, 191-194, 2015.

Z. Hu, W. Lu and M. D. Thouless, "Slip and Wear at a Corner with Coulomb Friction and an Interfacial Strength," Wear,338-339, 242-251, 2015.

Z. Hu, W. Lu and M. D. Thouless and J. R. Barber, "Effect of plastic deformation on the evolution of wear and local stress fields in fretting," International Journal of Solids \& Structures, 82, 1-8, 2016.

Z. Hu, H. Wang, M. D. Thouless and W. Lu,"An approach of adaptive effective cycles to couple fretting wear and creep in finite-element modeling,"manuscript submitted (2017).

A. B. Johnson, E. R. Gilbert and R. J. Guenther, "Behavior of spent nuclear fuel and storage system components in dry interim storage,” PNL-4189, Prepared for the U. S. Department of Energy under contract DE-AC06-76RLO 1830, Pacific Northwest Laboratory, Aug 1982. 
A. B. Johnson and E. R. Gilbert , "Technical basis for storage of Zircaloy-clad spent fuel in inert gases," PNL-4835 Prepared for the U. S. Department of Energy under contract DE-AC0676RLO 1830, Pacific Northwest Laboratory, Sep 1983.

J. J. Kearns and C. R. Woods, "Effect of texture, grain size, and cold work on the precipitation of oriented hydrides in zircaloy tubing and plate", Journal of Nuclear Materials, 20, 241-261, 1966.

Kyu-Tae Kim and Jung-Min Suh, "Impact of nuclear fuel assembly design on grid-to-rod Fretting Wear,”Journal of Nuclear Science and Technology, 46, 149-157, 2009.

Kyu-Tae Kim and Jung-Min Suh, "Development of an advanced PWR fuel for OPR1000s in Korea,"Nuclear Engineering and Design, 238, 2606-2613, 2008.

Kyu-Tae Kim, "The study on grid-to-rod fretting wear models for PWR fuel,"Nuclear Engineering and Design, 239, 2820-2824, 2009.

Young-Ho Lee andHyung-Kyu Kim, "Fretting wear behavior of a nuclear fuel rod under a simulated primary coolant condition,”Wear, 301, 569-574, 2013.

C. Paulin, S. Fouvry, C. Meunier, "Finite element modelling of fretting wear surface evolution: Application to a Ti-6A1-4V contact," Wear, 264, 26-36, 2008.

P. R. Rubiolo, and M. Y. Young, "On the factors affecting the fretting-wear risk of PWR fuel assemblies,"Nuclear Engineering and Design, 239, 68-79, 2009.

B. Stingl, M. Ciavarella, N. Hoffmann, "Frictional dissipation in elastically dissimilar oscillating Hertzian contacts,” International Journal of Mechanical Sciences, 72, 55-62, 2013.

A. Romano, C. Shuffler, H. Garkischc, D. Olander , N. Todreas, "Fuel performance analysis for PWR cores,” Nuclear Engineering and Design, 239, 1481-1488, 2009.

H. Wang, Z. Hu, W. Lu, and M.D. Thouless, “A mechanism-based framework for the numerical analysis of creep in zircaloy-4,”Journal of Nuclear Materials, 433, 188-198, 2013.

J. Yan, K. Yuan, E. Tatli and Z. Karoutas, "A new method to predict grid-to-rod fretting in a PWR fuel assembly inlet region,”Nuclear Engineering and Design, 241, 2974-2982, 2011. 


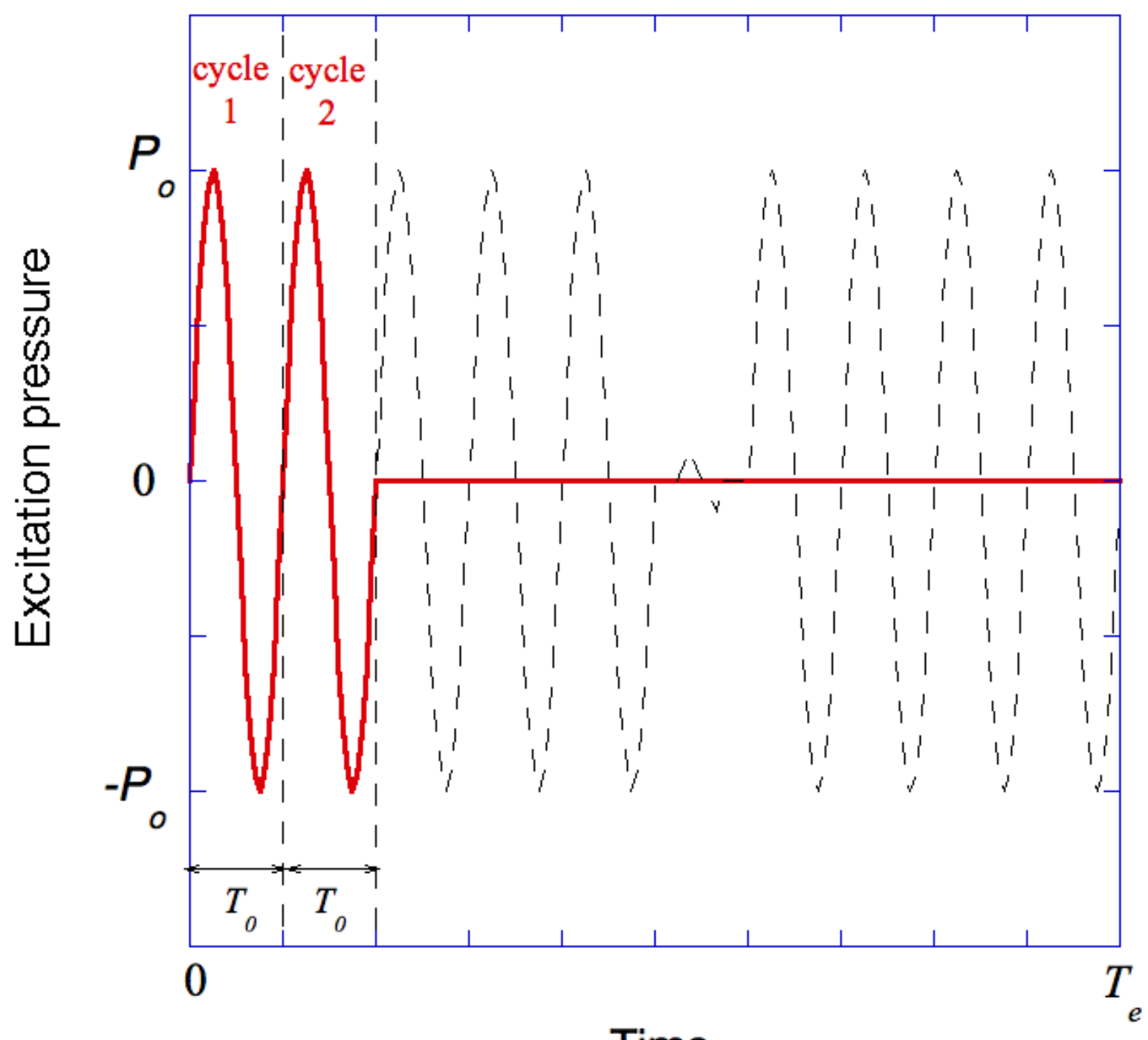

Time

Figure 1 The black,dashed line is the actual excitation force. The red, solid line is the assumed force historythat is used to couple wear and creep. Both creep and tangential loading can both induce relative displacements across the interface. Therefore, to separate the two effects, two actual cycles (with aperiod of $T_{0}$ )are simulated without creep. Steady-state is reached after the first cycle, so it is the second cycle that is used to compute wear damage from the oscillating force. After this second cycle, no further vibrations are assumed, but creep is allowed to occur. This results in some additional relative displacement and wear. The total wear is assumed to be given by the sum of the damage accumulated in the second cycle multiplied by a factor of $T_{e} / T_{0}$, plus the damage from associated with creep. The maximum value of $T_{e}$ is set by imposing a limit on the drop in local contact stresses. 


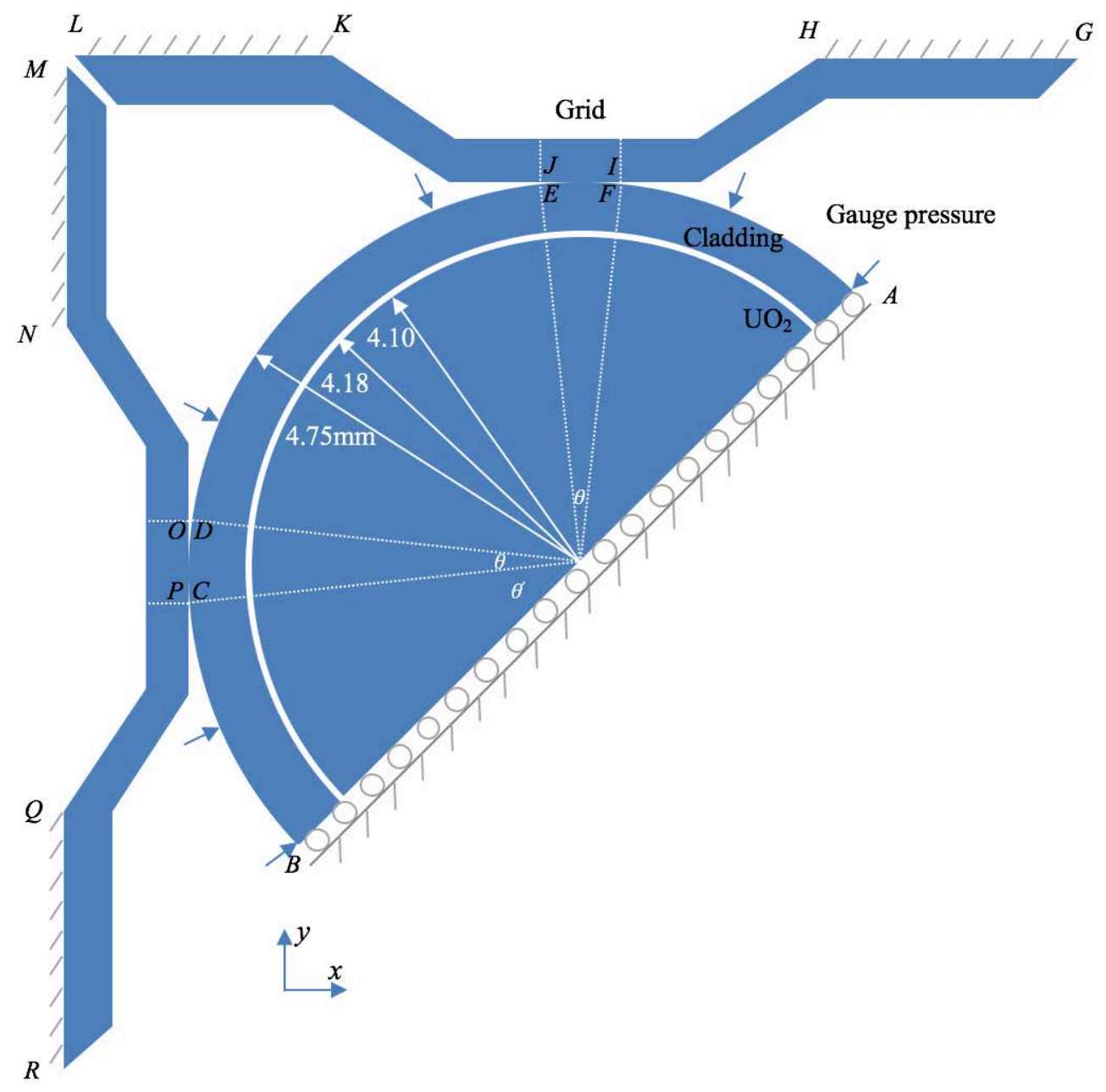

Figure 2: A diagram showing the assembly of the grid, cladding and $\mathrm{UO}_{2}$.Wear is simulated on the surfaces of $C D, O P, E F$ and $I J$. Symmetrical boundary conditions areenforced along $A B$. An oscillating pressure is applied along the surface $B C$ and AF. To apply the initial interference, the boundaries $M N$ and $Q R$ are displaced along $x$-direction, and the boundaries $L K$ and $G H$ are displaced along $y$-direction, with the misfit being defined by the distance each support has to be moved to join them at $L$ and $M$. The four boundaries are then fully-constrained before beginning the simulation.The angle $\theta$, defining the regions $D C$ and $E F$, has a value of $5^{\circ}$, while the angle $\theta$, defining the point $C$ has a value of $42.5^{\circ}$. 


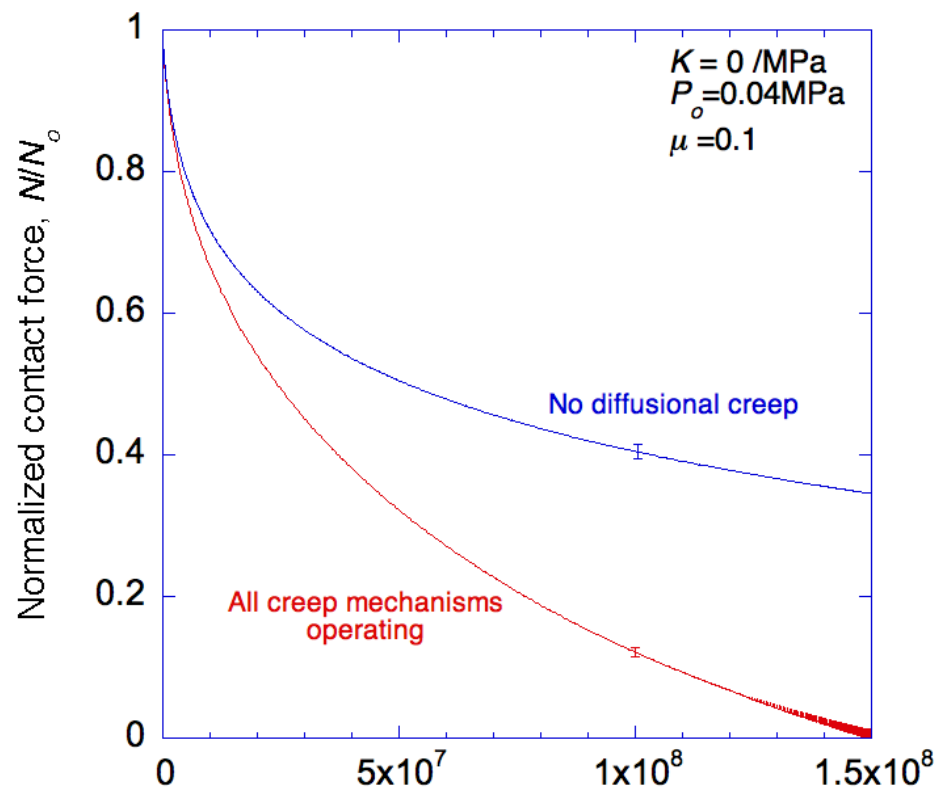

(a)

Normalized time, $t / T_{o}$

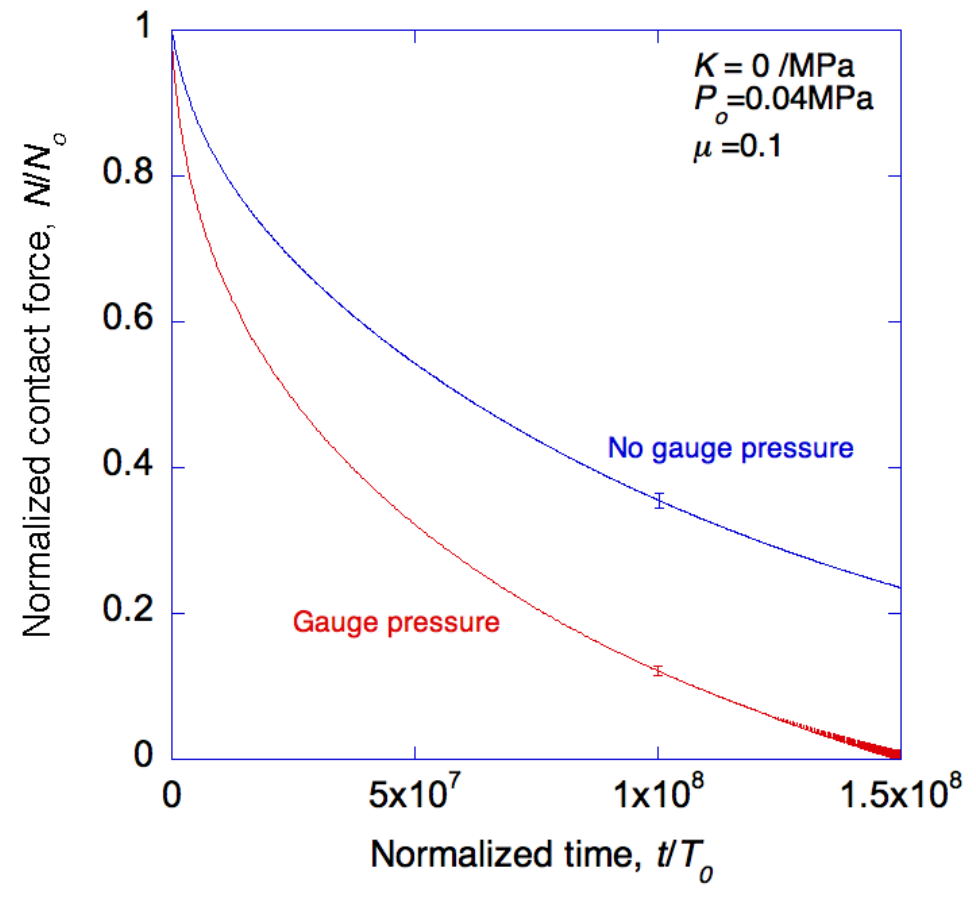

Figure 3: $\quad$ Plots of total contact force per unit thickness, $N$, time $t$ (a)Diffusional creep is important for the relaxation of the contact force. The stress drop to low levels much more slowly if diffusional creep mechanisms are ignored. (b) The role of creep-down is separated from the role of local stress relaxation at the contact by setting the gauge pressure to zero. It is clear that the creep-down process plays a dominant role in the relaxation of the stresses at the contacts.In these plots, the contact force is normalized by its initial value $\left(N_{0}=26.8 \mathrm{~N} / \mathrm{mm}\right)$, and the time is normalized by the period of the oscillations $\left(T_{o}=0.1 \mathrm{~s}\right)$. 


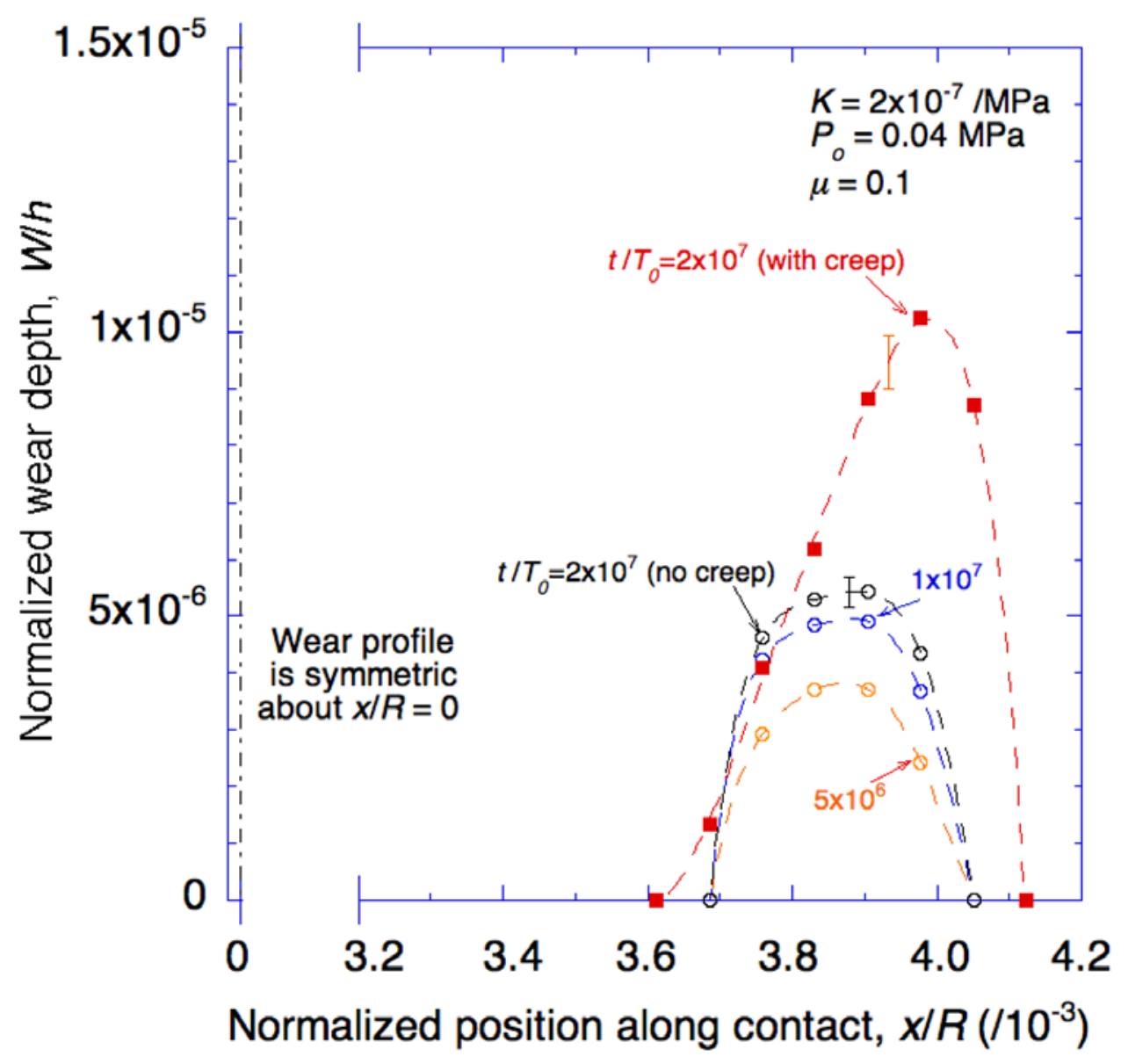

Figure 4: $\quad$ Creep causes the slip boundary to moves,so the wear scare propagates (solid square data points). In the absence of creep, the wear scar just gets deeper (open circular data points). In this plot the wear depth is normalized by the cladding thickness $(h=0.57 \mathrm{~mm})$, and the position from the center of the contact is normalized by the outer radius of the cladding $(R=4.75 \mathrm{~mm})$. 


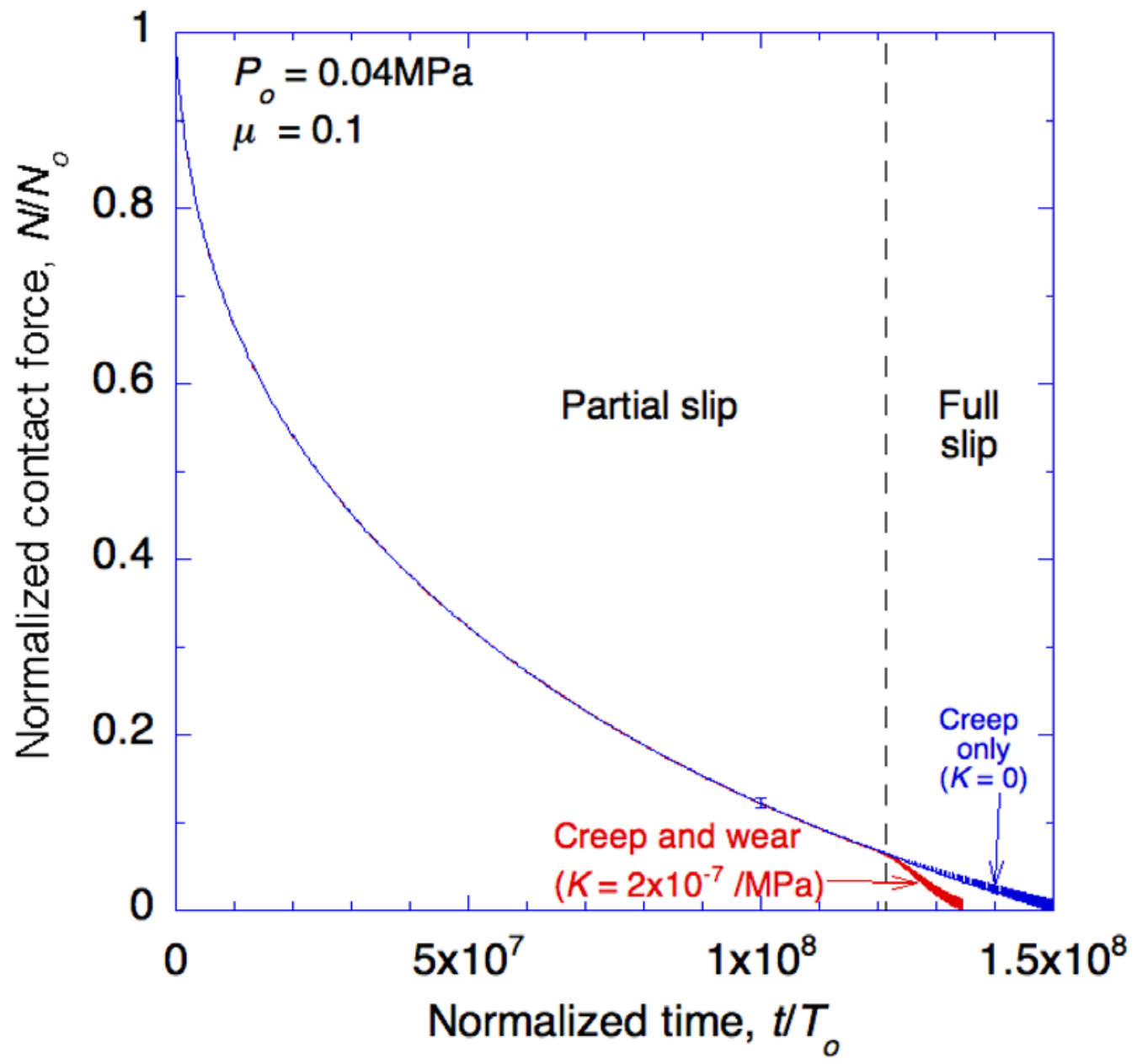

Figure 5: The effect of wear on the relaxation of the contact force. Initially, although there is local wear damage caused by partial slip, the wear damage is too small to cause significant relaxation.The stress relaxation is dominated by creep. The dramatic increase in the rate of relaxation just before gap formation occurs is associated with the onset of full slip. The contact force is normalized by its initial value, $N_{0}=26.8 \mathrm{~N} / \mathrm{mm}$, and the time is normalized by the period $T_{o}=0.1 \mathrm{~s}$. 


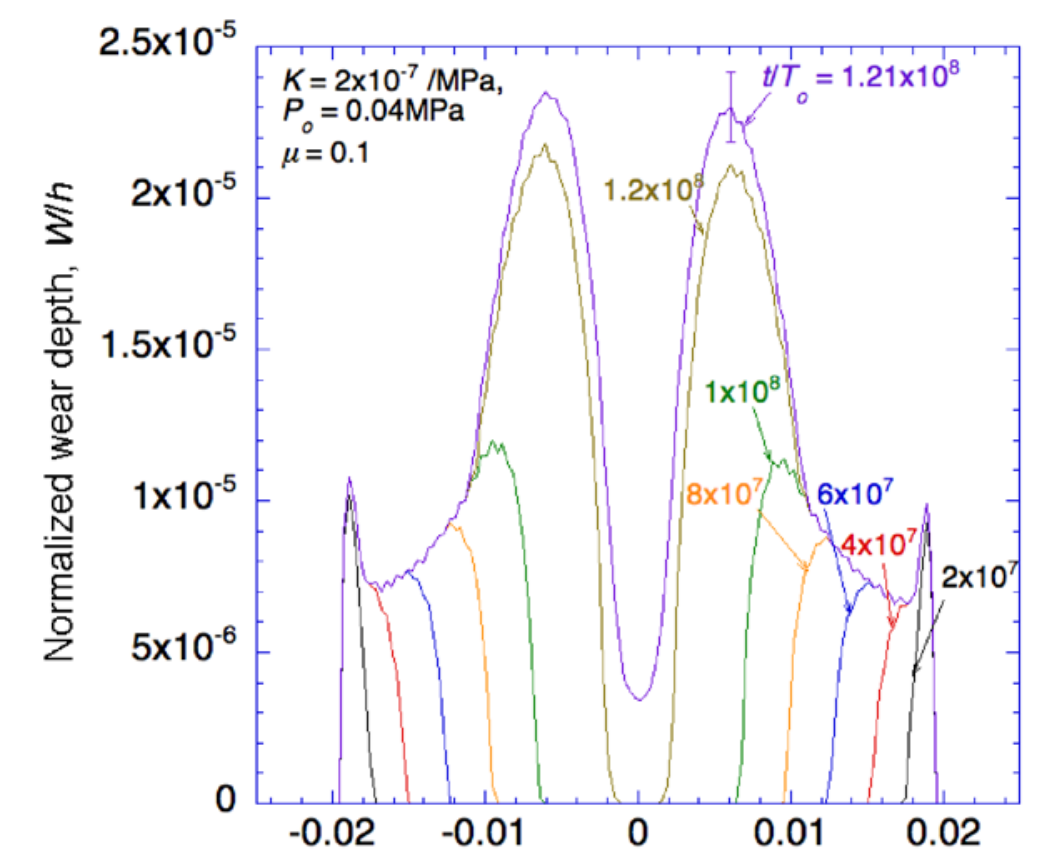

(a)

Normalized distance from center of contact, $x / R$

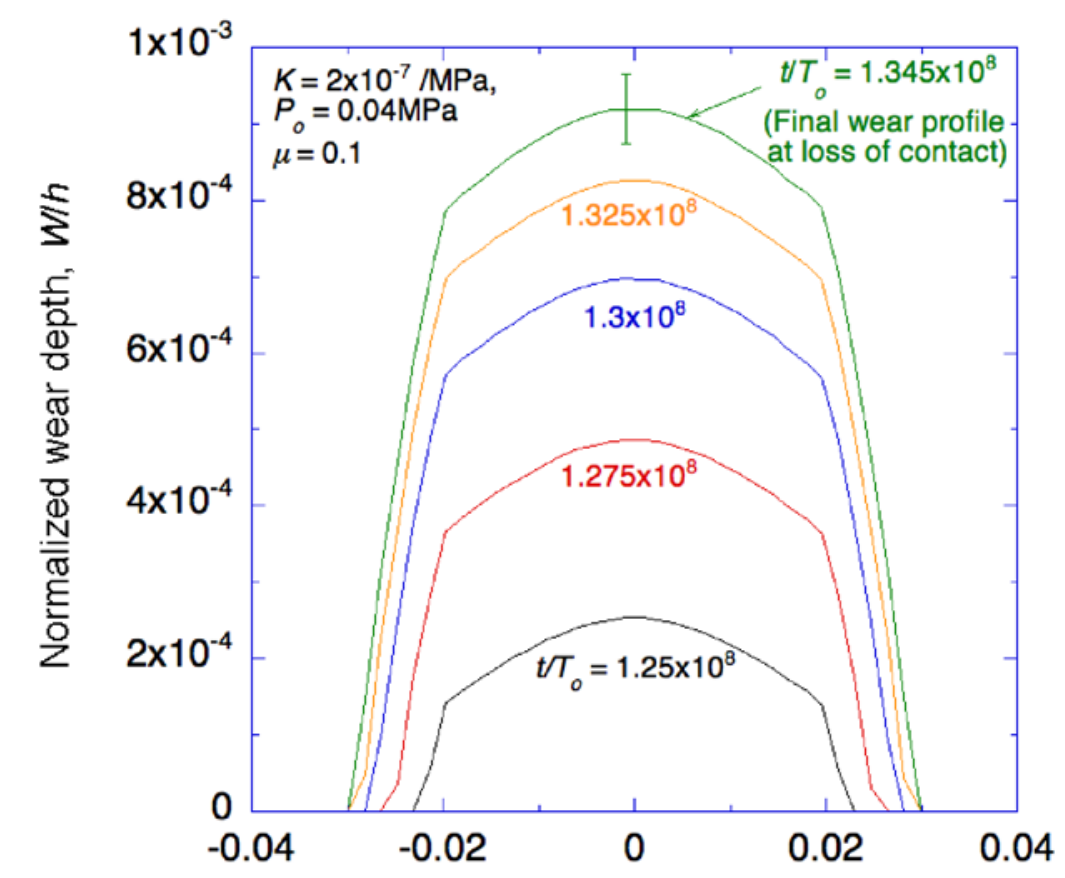

(b)

Normalized distance from center of contact, $x / R$

Figure 6: Wear profiles at different times. (a) Initially, wear occurs only at the edges of the contact. As the contact force is relaxed by creep, the wear scars expands into the middle. (b) At some point before they touch, full slip occurs, and wear then occurs over the entire interface, eventually evolving into a profile where the maximum wear depth is in the middle of the contact. In this plot the wear depth is normalized by the cladding thickness $(h=0.57 \mathrm{~mm})$, and the position from the center of the contact is normalized by the outer radius of the cladding $(R=4.75 \mathrm{~mm})$. 


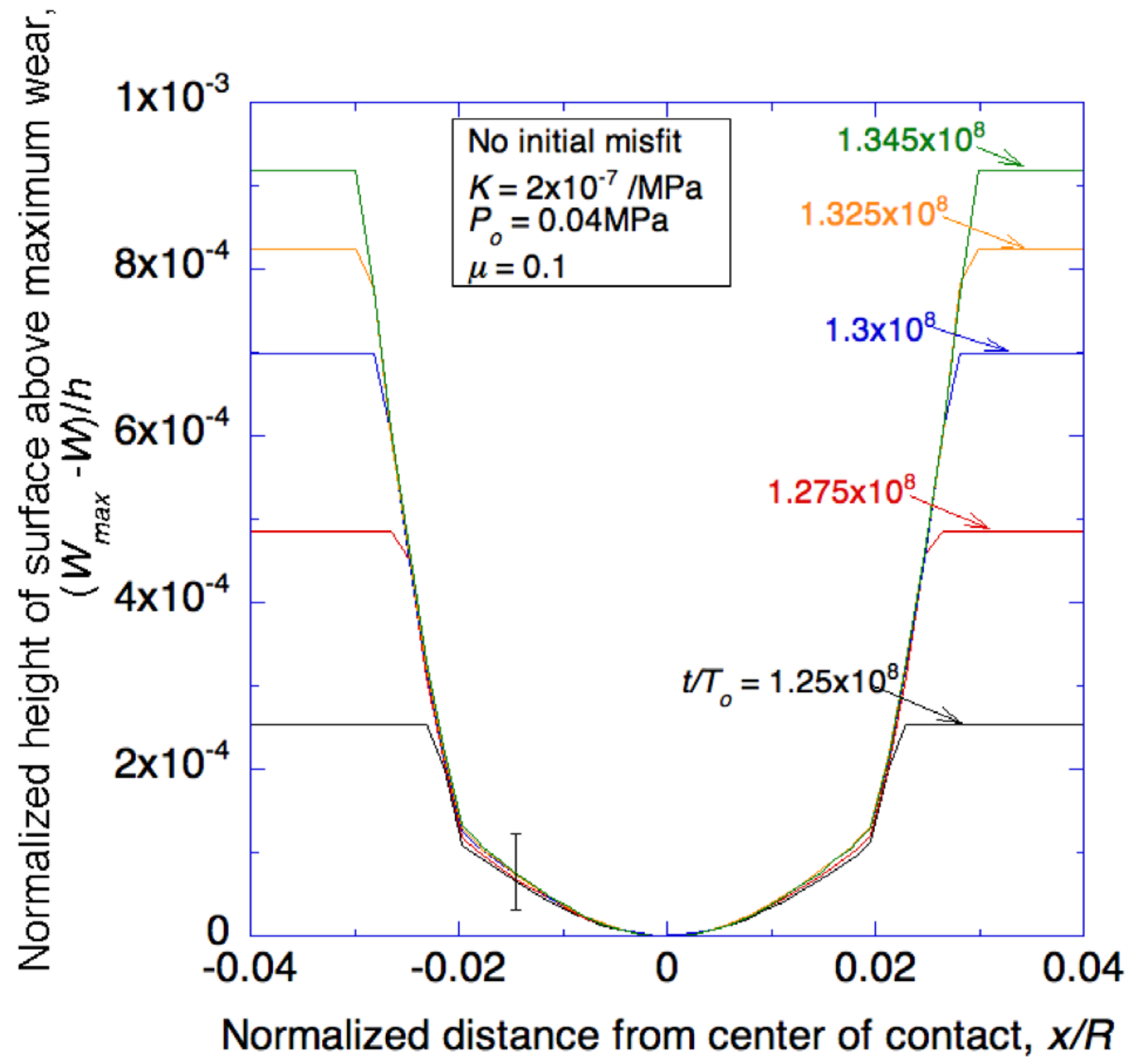

Figure 7: The wear profile evolves homogeneously after the onset of full slip. By subtracting the local wear depth from the maximum wear depth at any given moment, the wear profiles at different times collapse onto a master curve.This homogeneous evolution is attributed to a uniform dissipation of frictional energy. In this plot the wear depth is normalized by the cladding thickness $(h=0.57 \mathrm{~mm})$, and the position from the center of the contact is normalized by the outer radius of the cladding $(R=4.75 \mathrm{~mm})$. 


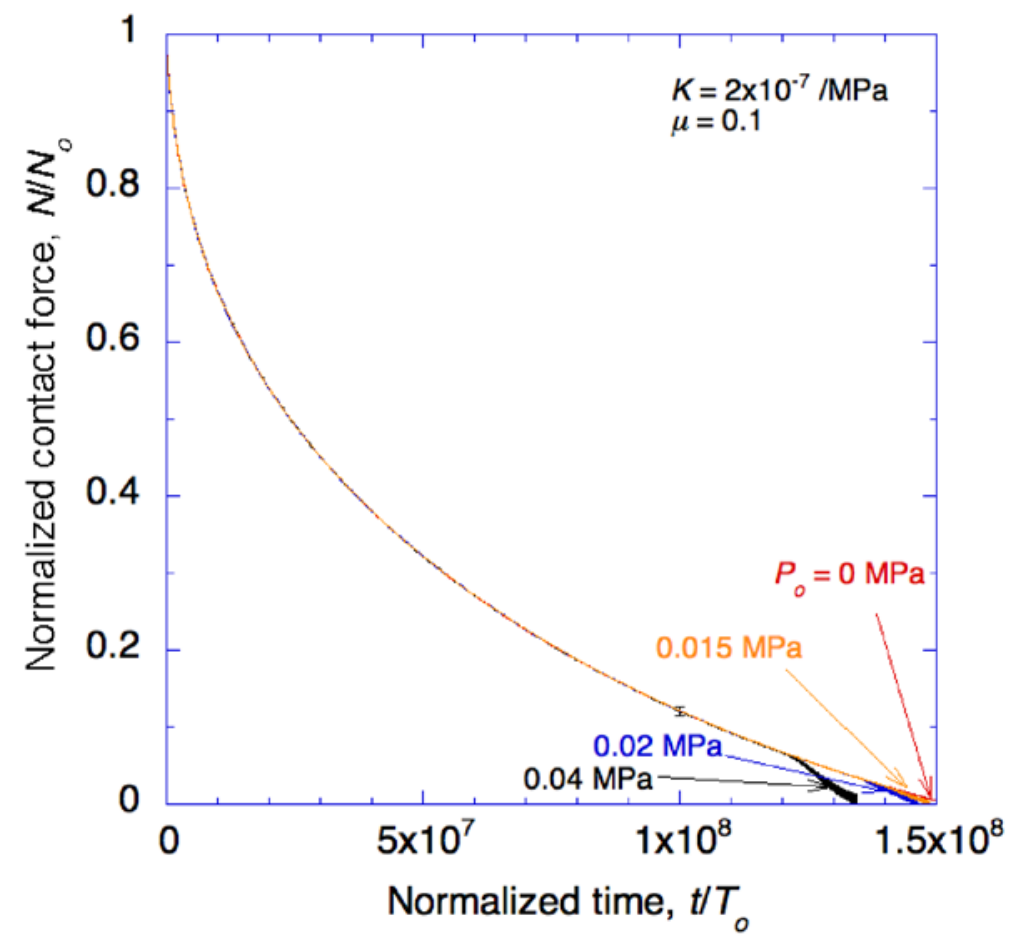

(a)

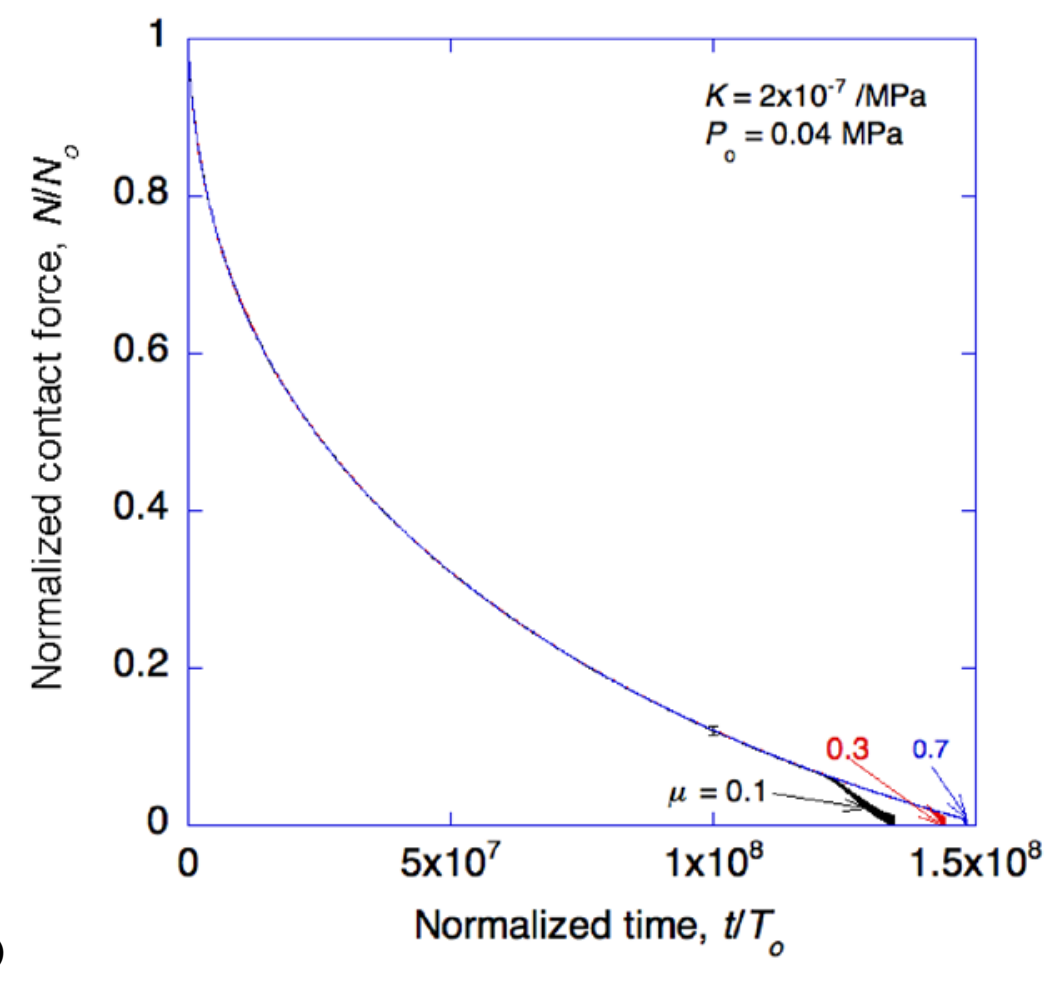




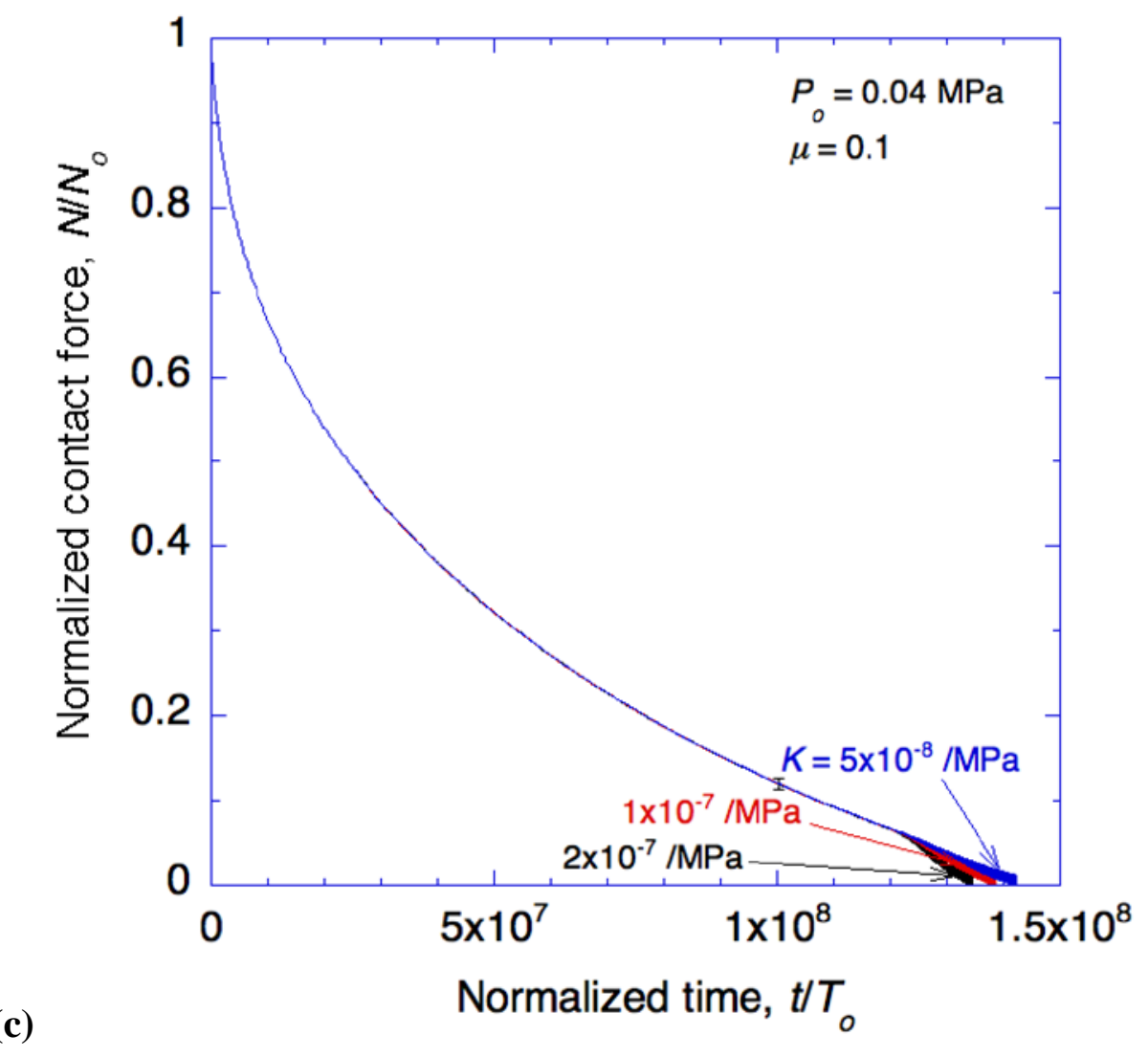

Figure 8: The effect of (a) the amplitude of the excitation force, (b) the friction coefficient, and (c) the wear coefficient on the relaxation of the contact force as a function of time, for no initial misfit.The contact force is normalized by the initial contact force $\left(N_{o}=26.8 \mathrm{~N} / \mathrm{mm}\right)$ The onset of full slip is delayed by a drop in the amplitude of the excitation force and by an increase in the friction coefficient, leading to a longer time before contact is lost. Conversely, while a decrease in the wear coefficient extends the time until contact is lost, it has no effect on the onset of full slip. 


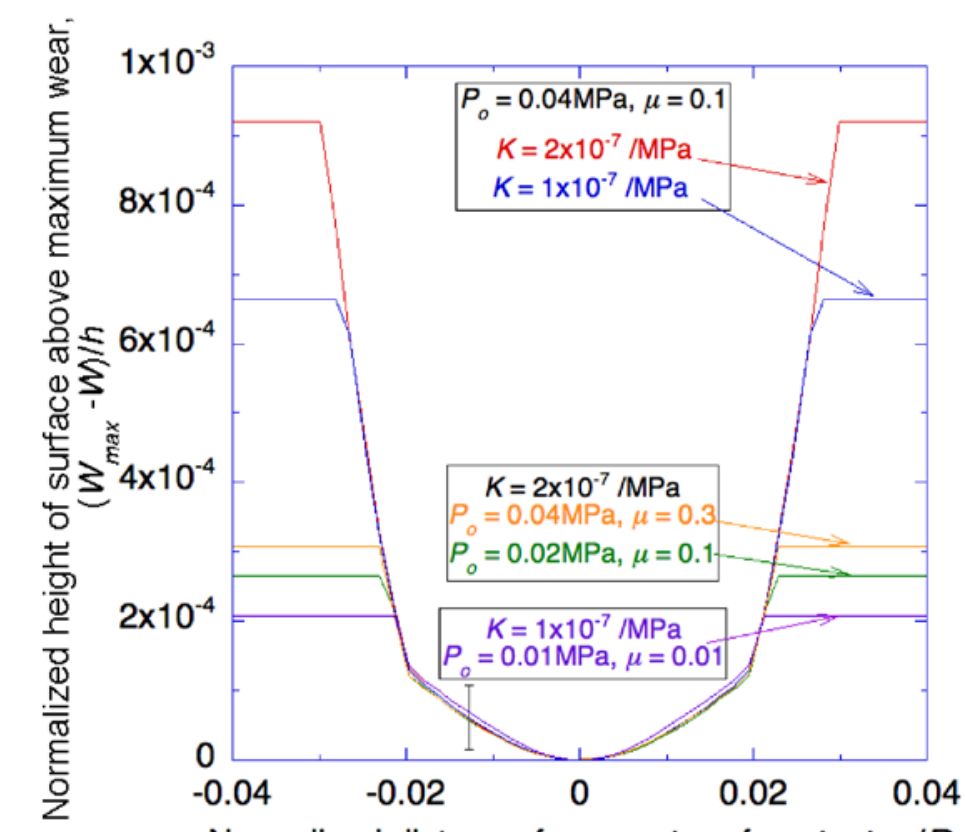

(a)

Normalized distance from center of contact, $x / R$

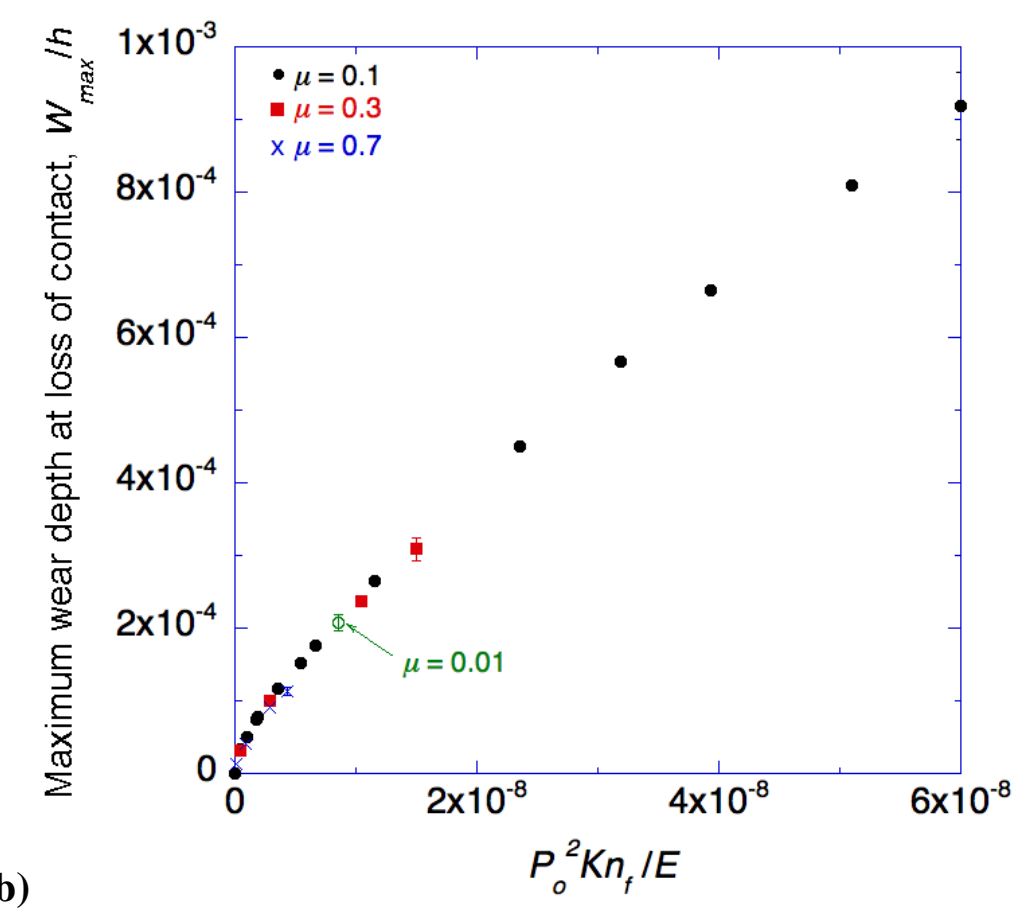

Figure 9: (a)Plots of the wear profiles with no initial misfit at the time when contact is lost, for different magnitudes of the wear coefficient, friction coefficient and excitation force. None of these variables affect the shape of the master curve.(b) The maximum wear depth depends on the square of the amplitude of the excitation pressure, the wear coefficient and the number of cycles of full slip until contact is lost, $n_{f}$. The number of cycles of full slip depends on the friction coefficient. $E$ is Young's modulus of zircaloy. 


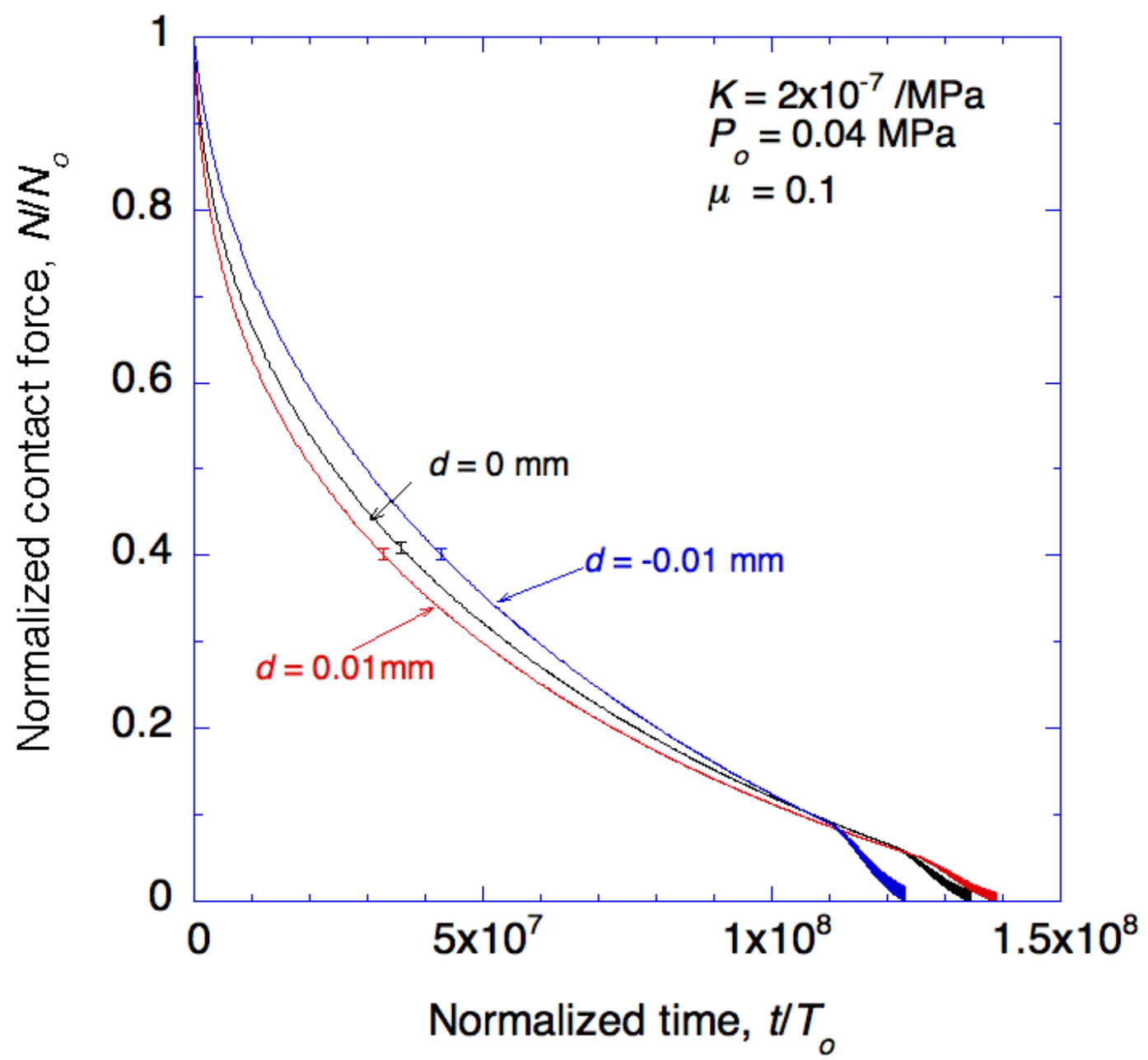

Figure 10: The introduction of an initial misfit during assembly (corresponding to a positive value of $d$ ) slightly delays the formation of a gap during service. However, the effect is not large, because the increase in initial residual stress results in an increased power-law-creep rate. Conversely, an initial gap(corresponding to a negative value of $d$ )will initially be closed up by the thermal expansion, but significantly shortens the time taken to open up a gap during service. The initial values of $N_{o}$ used to normalize the contact forces in this plot are $26.8 \mathrm{~N} / \mathrm{mm}$ when $d=0 \mathrm{~mm}, 32.2 \mathrm{~N} / \mathrm{mm}$ when $d=0.01 \mathrm{~mm}$, and $19.2 \mathrm{~N} / \mathrm{mm}$ when $d=-0.01 \mathrm{~mm}$. 


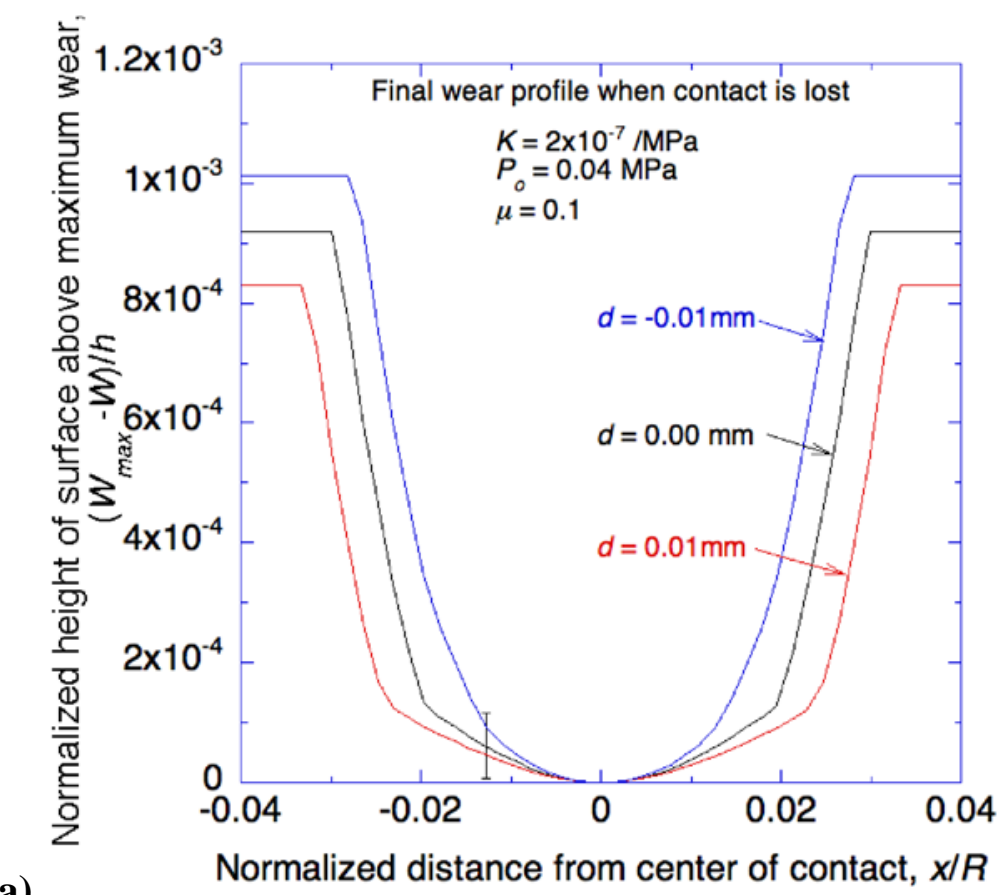

(a)

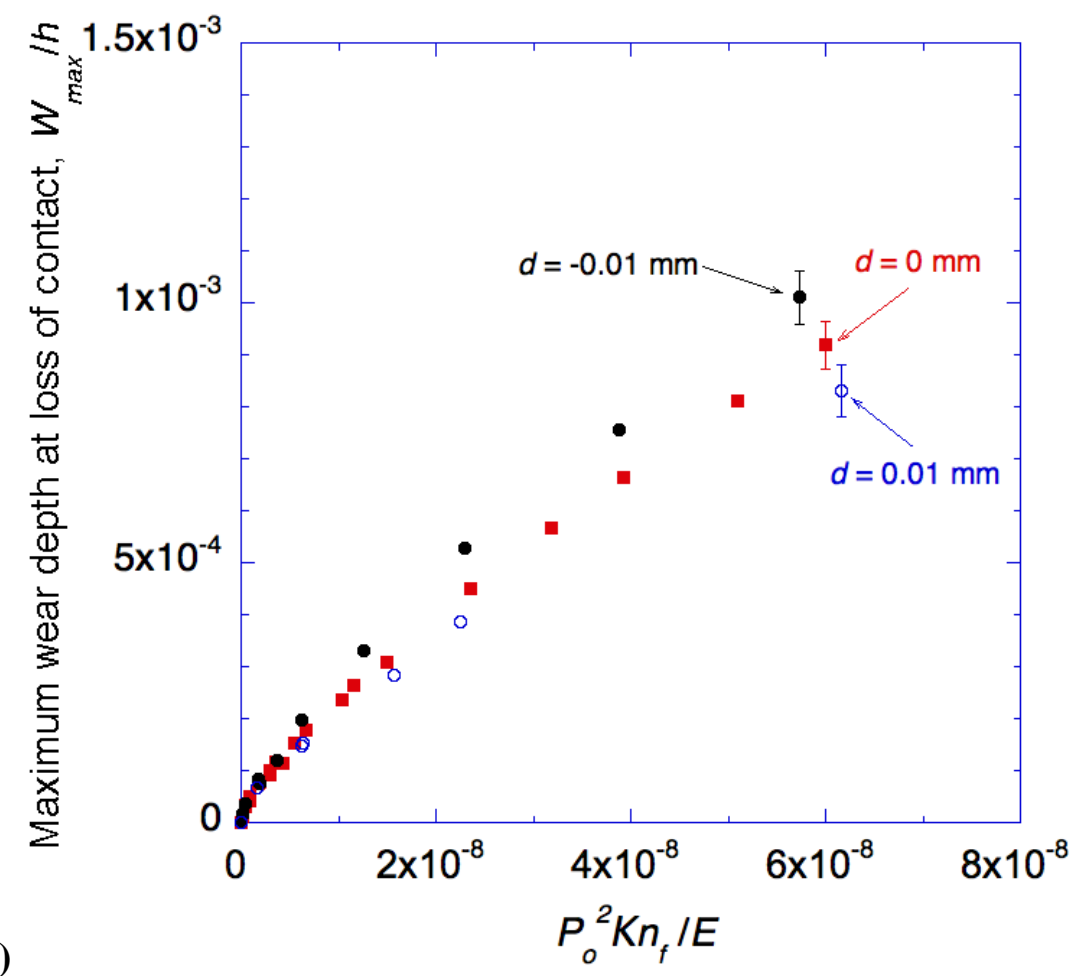

Figure 11: The magnitude of the initial misfit can change (a) the shape of the master curve for the wear profile, and (b) the maximum wear depth for loss of contact. The difference is due to the initial misfit only. In this plot, $n_{f}$ is the number of cycles of full slip required for contact to be lost and $E$ is Young's modulus of zircaloy. 


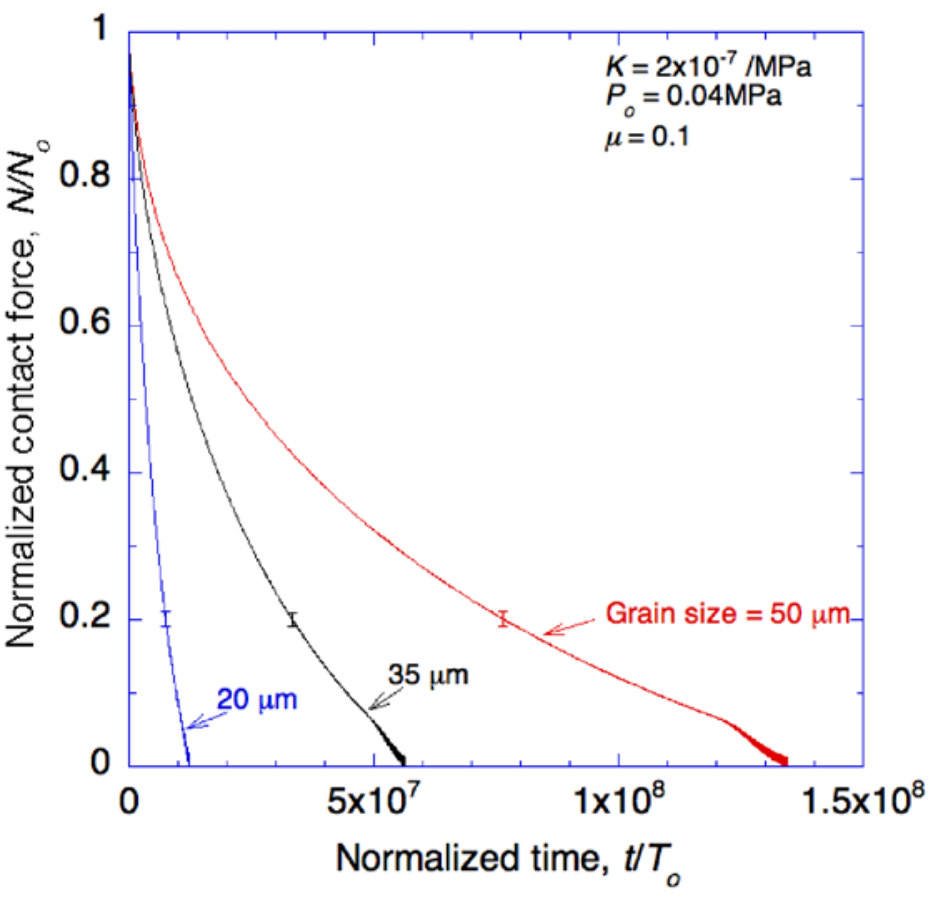

(a)

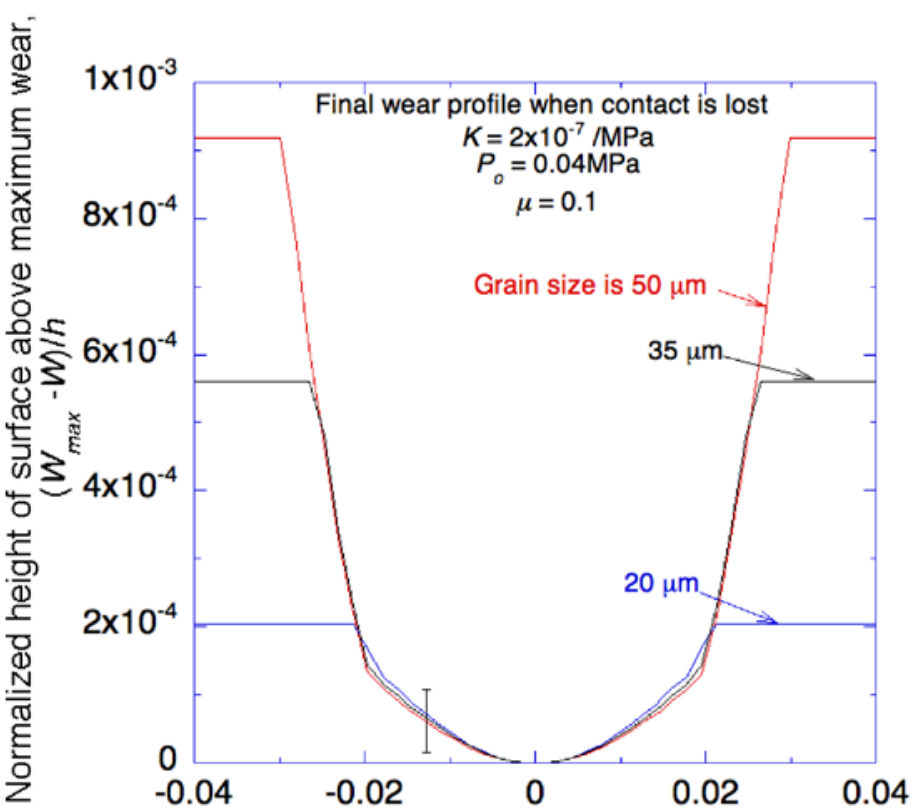

(b)

Normalized distance from center of contact, $x / R$

Figure 12: (a) The effect of the zircaloy grain size on the relaxation of the contact force as a function of time, for no initial misfit. The contact force is normalized by the initial contact force $\left(N_{o}=26.8 \mathrm{~N} / \mathrm{mm}\right)$. Since the diffusional creep rate increases as the grain size decreases, the time for full relaxation decreaseswith grain size. (b) As the creep rate increases with smaller grains, the amount of wear that occurs before a gap is formed also decreases. 


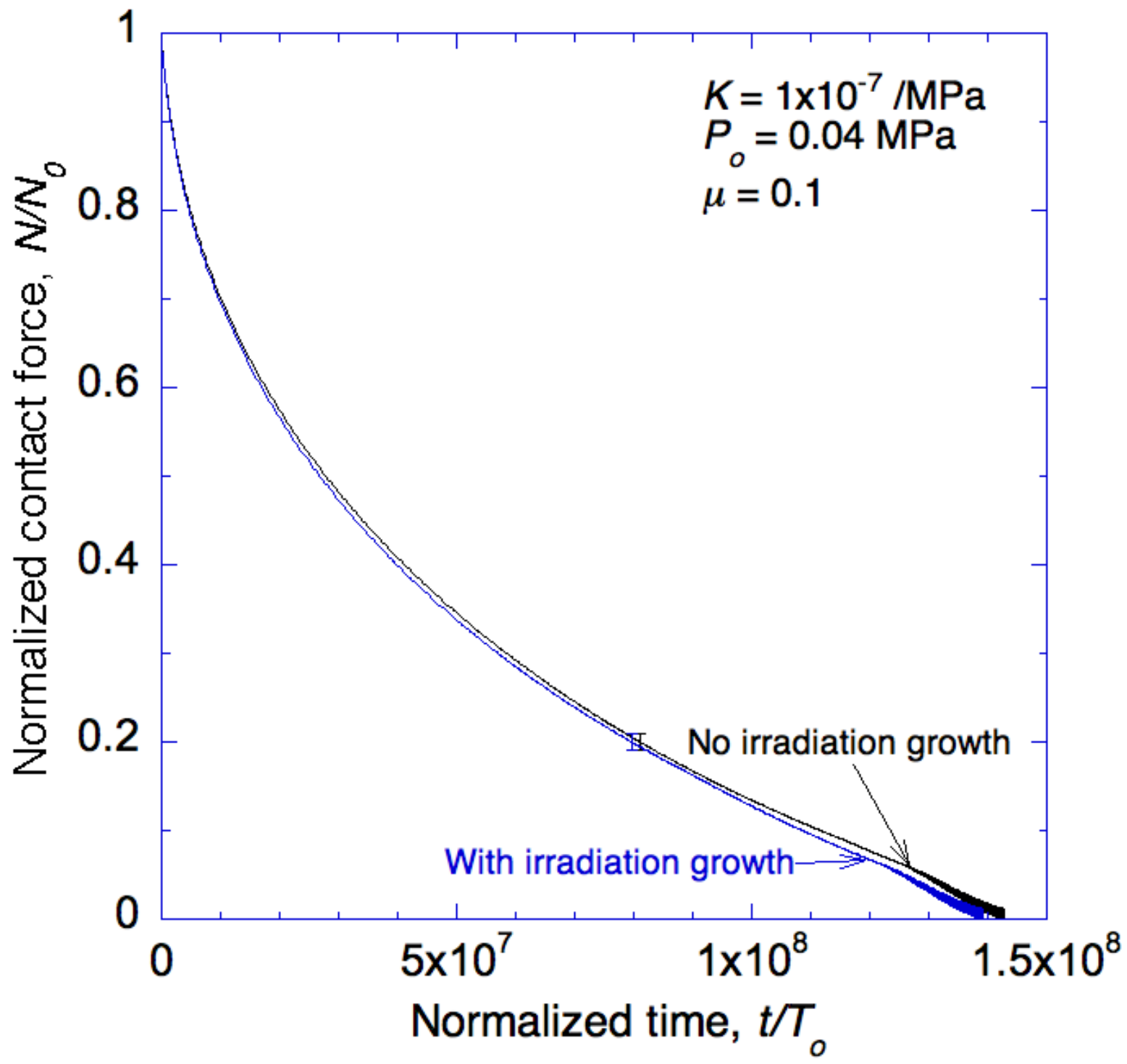

Figure 13: For the parameters chosen in this paper, irradiation growth does not appear to make a significant contribution to the relaxation of the contact force,nor to the time taken toform a gap. The initial contact force for this case is $27.5 \mathrm{~N} / \mathrm{mm}$. (This is slightly larger than the corresponding initial contact force in earlier figures, because of effects of anisotropy in the thermal expansion.) 

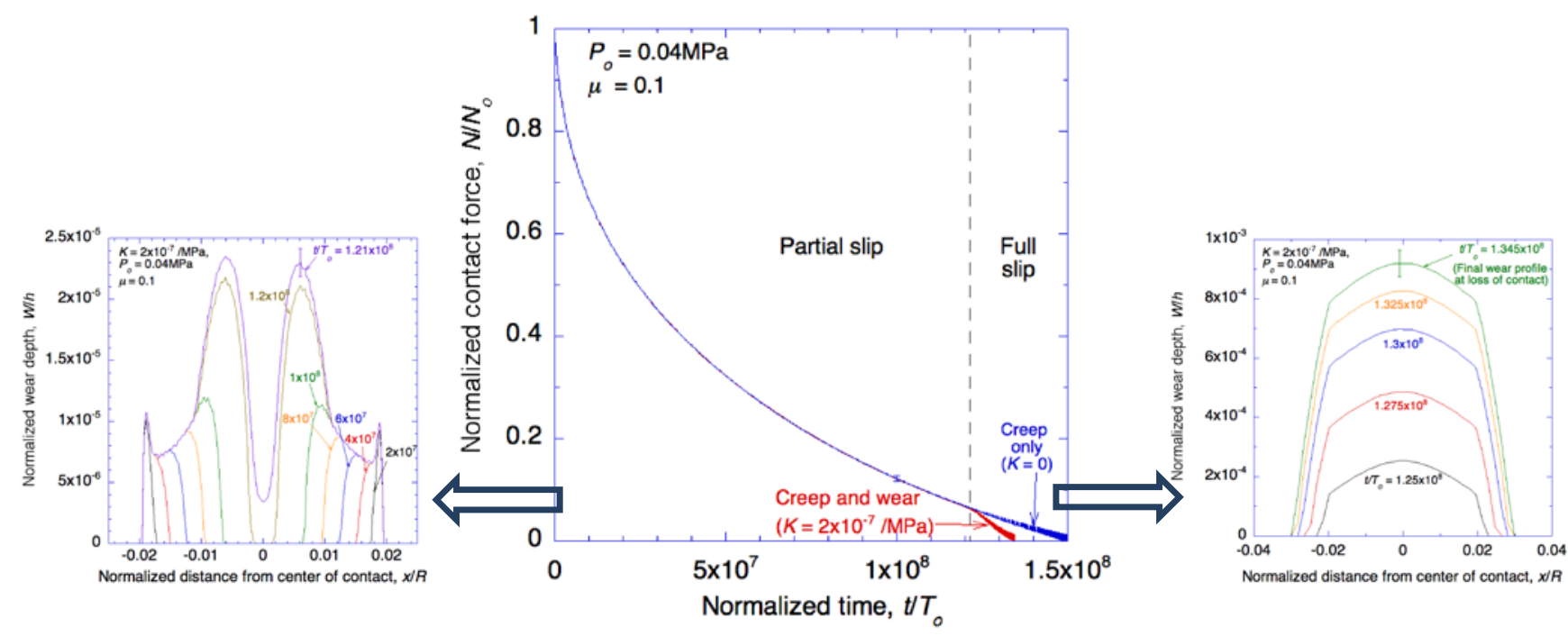

Integrated wear and creep analysis shows the relaxation of contact force over time during grid-to-rod fretting. Initially, wear occurs only at the edges of the contact. As the contact force is relaxed by creep, the wear scars expands into the middle. At some point full slip occurs, and wear then occurs over the entire interface, eventually evolving into a profile where the maximum wear depth is in the middle of the contact.Contact relaxation is dominated by creep at the partial slip stage and by wear at the full slip stage. 